\title{
Surveillant landscapes
}

Article

Accepted Version

Jones, R. H. (2017) Surveillant landscapes. Linguistic Landscapes, 3 (2). pp. 149-186. ISSN 2214-9953 doi: https://doi.org/10.1075/ll.3.2.03jon Available at https://centaur.reading.ac.uk/70420/

It is advisable to refer to the publisher's version if you intend to cite from the work. See Guidance on citing.

Published version at: https://benjamins.com/\#catalog/journals/ll.3.2.03jon/details

To link to this article DOI: http://dx.doi.org/10.1075/II.3.2.03jon

Publisher: John Benjamins

All outputs in CentAUR are protected by Intellectual Property Rights law, including copyright law. Copyright and IPR is retained by the creators or other copyright holders. Terms and conditions for use of this material are defined in the End User Agreement.

\section{www.reading.ac.uk/centaur}

\section{CentAUR}

Central Archive at the University of Reading

Reading's research outputs online 


\title{
Surveillant Landscapes
}

\author{
Rodney H. Jones \\ University of Reading
}

To appear in Linguistic Landscapes

\begin{abstract}
Most linguistic landscape research to date has focused on how people read and write language in the material world. Much less attention has been paid to the way linguistic landscapes sometimes read and write their inhabitants through technologies like CCTV cameras, intruder alarms, and other aspects of the built environment designed to make people 'visible'—what I call surveillant landscapes. This article puts forth a framework for analyzing the surveillant nature of linguistic landscapes based on tools from mediated discourse analysis. It sees surveillant landscapes in terms of the way they communicate practices of surveillance to the people who inhabit them ('discourses in place'), the kinds of social relationships and social identities that they make possible ('interaction orders'), and the ways architectures of surveillance come to be internalized by citizens, while at the same time aspects of their behaviors and identities come to be sedimented into their environments ('historical bodies'). I argue that studies of linguistic landscapes should take more account of the agenitive nature of linguistic landscapes and their increasing ability to recognize and to entextualize what takes place within them, and the consequences of this both on situated social interactions and on broader political and economic realities.
\end{abstract}

Keywords: CCTV, digital technologies, linguistic landscapes, mediated discourse analysis, surveillance

\section{Introduction}


When the term 'Linguistic Landscapes' was first coined in the late 1990's it was used to talk about the way the language of public road signs, advertising billboards, street and place names, and commercial signs, combine to form the linguistic landscape of a given territory, region or city. Since then definitions of linguistic landscapes have expanded to include not just other aspects of the built environment, (buildings, sounds, smells) but also the ways built environments shape how people interact with and in them, and how linguistic landscapes both index and, to some degree, constitute those who inhabit them (see Ben-Rafael, et al., 2006; Shohamy and Gorter eds., 2008). Blommaert (2013:23), for example, has called upon linguistic landscape researchers to see space as 'an actor, as something that operates as a material force on human behavior performed in spaces.' Most linguistic landscape research, however, is still focused on people reading and writing landscapes - whether it be inhabitants of cities navigating their way though or negotiating their identities with linguistic signs in their environments, or linguists reading linguistic landscapes as evidence of sociolinguistic or sociopolitical phenomena. Much less attention has been paid to the way landscapes read and write their inhabitants - that is, the the aspects of built environments that are designed to make people and their actions visible and legible, what I will be calling surveillant landscapes.

When we think of spaces that are capable of 'reading' their inhabitants we are likely to think first of spaces that are equipped with digital cameras, intruder alarms, or other kinds of sensors that gather information and to transmit it to remote locations, and many of the landscapes I will be describing in this paper are precisely of this kind. It does not require sophisticated technology, however, to make a place into a surveillant landscape. Even the most basic of architectural features, windows, street lamps, and tiny openings like keyholes can be used to make people and their actions visible and legible (Locke, 2010; Markus, 1994; Markus \& Cameron, 2002). In his book The Victorian Eye: A political history of light and vision in England, for example, Chris Otter (2008) describes how the introduction of gas lights on city streets in Victorian England created new regimes of 
visibility, transforming space that had before been, at least at night, somewhat private, into 'public' space. The implication here, of course, is that public space is, by its nature surveillant space-what makes it public is the way it makes visibility possible. Similarly, urban planning in most industrial countries since the 1970s has been dominated by attempts to turn architecture to the service of crime prevention by creating what architect Oscar Newman (1972) calls 'defensible spaces', spaces that are built to maximize the exposure of the people who inhabit them and thus minimize the opportunities for those people to engage in 'antisocial behavior'. In fact one could even argue, along with Lefebvre (1991:75) that all spaces 'are made with the visible in mind,' designed to make the people and things contained within them visible (or invisible) to particular people.

Perhaps the most famous treatment of a surveillant landscape is Michel Foucault's (1995) discussion of Jeremy Bentham's panopticon, an architectural structure which, through its emplacement of walls, windows, and a central observation tower, creates the conditions by which prisoners are made visible to guards, but guards are made invisible to prisoners. Perhaps Foucault's most important insight, and the one most relevant to the study of surveillant landscapes, is that the panopticon operates not just by creating visibility but also by communicating it. The primary disciplining force upon the prisoners comes not from the guards, but from their own awareness of being watched, in the same way that surveillance cameras in public places discipline inhabitants not just by making them visible but by telling them that they are visible through signs that typically have pictures of cameras and warnings such as 'this premises is under CCTV surveillance' (Cole, 2002; see below).

Another important insight that Foucault offers is the reminder that surveillant landscapes operate as much through invisibility as through visibility. In the case of the panopticon, discipline functions not just through making the guards invisible to the prisoners, but also by making the prisoners invisible to each other. Both visibility and invisibility are double-edged swords. Visibility can make 
us safe, but it can also make us vulnerable. Invisibility can be used by the powerful to obscure the operation of their power, or it can be imposed upon the powerless in order to further disempower them. The way surveillant landscapes like the panopticon function to construct particular 'orders of visibility' (Kerfoot \& Hyltenstam, 2017) involves the combination of at least three elements: the material (and semiotic) dimension of the space which creates openings, obstacles, and 'lines of sight' and communicates the potential for visibility or invisibility to inhabitants, the social dimension of the space which facilitates particular kinds of (power) relationships between inhabitants (or between inhabitants and non-present others), and the psychological dimension, the way inhabitants internalize these orders of visibility.

Visibility, however, represents only half of the equation through which surveillant landscapes operate. The other half involves the way built environments render the behavior and identities of their inhabitants meaningful; the way they make people legible. The issue of legibility is particularly salient when we consider the ways public (and even private) spaces are increasingly 'augmented' by digital technologies that are able to 'translate the physical space and its dwellers into data' (Manovich, 2006: 221), while at the same time rendering their own operations 'illegible' (Markus \& Cameron, 2002; Sennett, 1998). Examples of such 'augmented spaces’ include checkpoints which collect biometric information in the form, for example, of fingerprints, such as those in many airports and some workplaces, smart homes which recognize the voices and record the behaviors of their owners, and nearly every place where people carry smart phones with wireless data connections. At the same time, legibility can also be created through less high-tech means: nearly every physical environment, in fact, contributes to imbuing our behavior with meaning. Acting 'nervous' at a customs checkpoint, for example, means something quite different from acting nervous in a dentist's office. All environments contribute to imposing on their inhabitants a certain set of rules for social conduct and assumptions about social identity (governing who is supposed to be in a particular place and how they are supposed to act), thus rendering some 
kinds of people and some forms of behavior as unmarked and others as marked. In his classic Seeing Like a State, James Scott (1999) speaks of how making places and their inhabitants legible through such devices as population registers, property laws, the design of cities and the organization of transportation is a central component in the operation of state power and and in the construction of citizenship. A similar point is made by Otter (2008), who argues that along with the visibility afforded by gaslights, the lives of citizens the Victorian era was also made 'legible' (and thus, 'inspectable') through innovations like street signs, house numbers and practices of record keeping. Finally, Michel de Certeau (1984:97) speaks both of 'the (voracious) property that the geographical system has of being able to transform action into legibility', and of the way spaces organize ensembles of possibility which conspire to 'secretly structure the determining conditions of social life' (96). Like visibility, legibility also operates at the intersection of the material, social, and psychological dimensions of built environments.

This article aims to suggest a framework for understanding these three interrelated dimensions of surveillant landscapes based on principles from mediated discourse analysis, a perspective which focuses on how social actions occur at specific 'sites of engagement', moments in time and space when particular material and semiotic conditions ('discourses in place'), particular social conditions ('interaction orders'), and and particular psychological conditions (the 'historical bodies' of individuals) come together to make certain actions, certain identities, and certain social relationships possible (Jones, 2005; Scollon, 2001; Scollon \& Scollon, 2003, 2004). The data for this discussion consists of 352 pictures that I have collected on city streets in shops, airports, parks, and public transport, in the UK, the US, Hong Kong, New Zealand, Sweden, and Germany of signs, cameras, mirrors, windows, architectural structures and other aspects of the built environment that seemed to me at the time have the purpose of making the inhabitants of a particular place visible and/or legible. I do not claim any systematic objectivity to my collection method. Rather my claim is for phenomenological validity. Surveillant landscapes are, as I argued above, by their very nature 
interactive, operating either through alerting inhabitants to the fact that they are being watched, or by concealing this fact from them (and sometimes doing both at the same time). Collecting examples of surveillant landscapes, therefore, requires being sensitive not just to explicit evidence of surveillance, but also to the possibilities for surveillance built into the architecture. It requires transversing the urban landscape as de Certeau (1984) describes, sensitive to the ways the environment is generated out of the strategies of governments, corporations, and other institutional bodies, and engaging in tactics of interpretation designed to make these strategies visible.

\section{Discourses in Place}

When I speak of discourses in place I am referring to the semiotic dimension of surveillant landscapes, the way they 'speak to us', sometimes directly, and at other times more indirectly. This includes not just the way semiotic aspects of the environment alert us that we are being watched, but also the ways they operate to encourage us to make ourselves more compliant objects of surveillance. Figure 1.1, taken on a bus from Reading, UK to Heathrow Airport, is typical of the kind of 'semiotic aggregate' (Scollon and Scollon 2005: 181) that marks particular public places as surveillant landscapes. The most obvious marker of surveillance in this photo, of course is the small sign announcing: 'For your comfort and peace of mind during your journey CCTV is fitted to this bus,' underneath an iconic picture of a surveillance camera (which, by the way, looks nothing like the cameras fitted to the bus). Less obvious, however, is the way the other signs in this photo are also somehow implicated in practices of surveillance. The sign warning passengers not to 'distract the driver's attention, stand forward of this notice,' or 'leave items in the aisle' as well as the 'no smoking sign', the universal image of a cigarette with a red line drawn through it, also include the implication that someone (either the camera or the driver) is watching passengers to make sure that they do not engage in these prohibited activities. Even the sign informing passengers of the location of the fire extinguisher positions them as responsible for keeping an eye out for fires and being ready to help to extinguish them. Not all of the signs however constitute warnings regarding 
surveillance. Others function more like invitations, offering passengers benefits for making themselves easier to surveil. This is the case with a small sign that says 'Wi-Fi zone', as well as the two identical signs below it asking passengers to 'Download the mTicket app now!'. Although passengers may not be entirely aware of this, availing themselves either of the free Wi-Fi provided on the bus or downloading the bus company's handy app to purchase their tickets will subject them to forms of surveillance far beyond the capabilities of the CCTV cameras fitted to the bus. When passengers login to the $\mathrm{Wi}-\mathrm{Fi}$, for example, they are asked to provide all sorts of personal information including their name, gender, email address, and date of birth, which may later be sold to data brokers or online advertisers. When passengers download the mTicket app, it asks them to allow it access to their phone's location data, theoretically allowing the bus company to track the passenger long after they have disembarked from the bus. At the same time not all of the semiotic modes used to communicate surveillance are verbal or graphic. Sometimes surveillance is communicated through physical objects or the embodied actions of human beings. Before the bus left on his journey from Reading to the airport, the driver announced that it was a legal requirement that all passengers fasten their seat belts before the bus set off, and while he said this he gazed into the rear view mirror that was affixed above the windshield, a mirror which presumably allowed him to check whether or not we were complying. In this regard, the mirror communicates the possibility of surveillance, and the driver gazing at us through it communicates its instantiation (see Figure $1.2)$. 

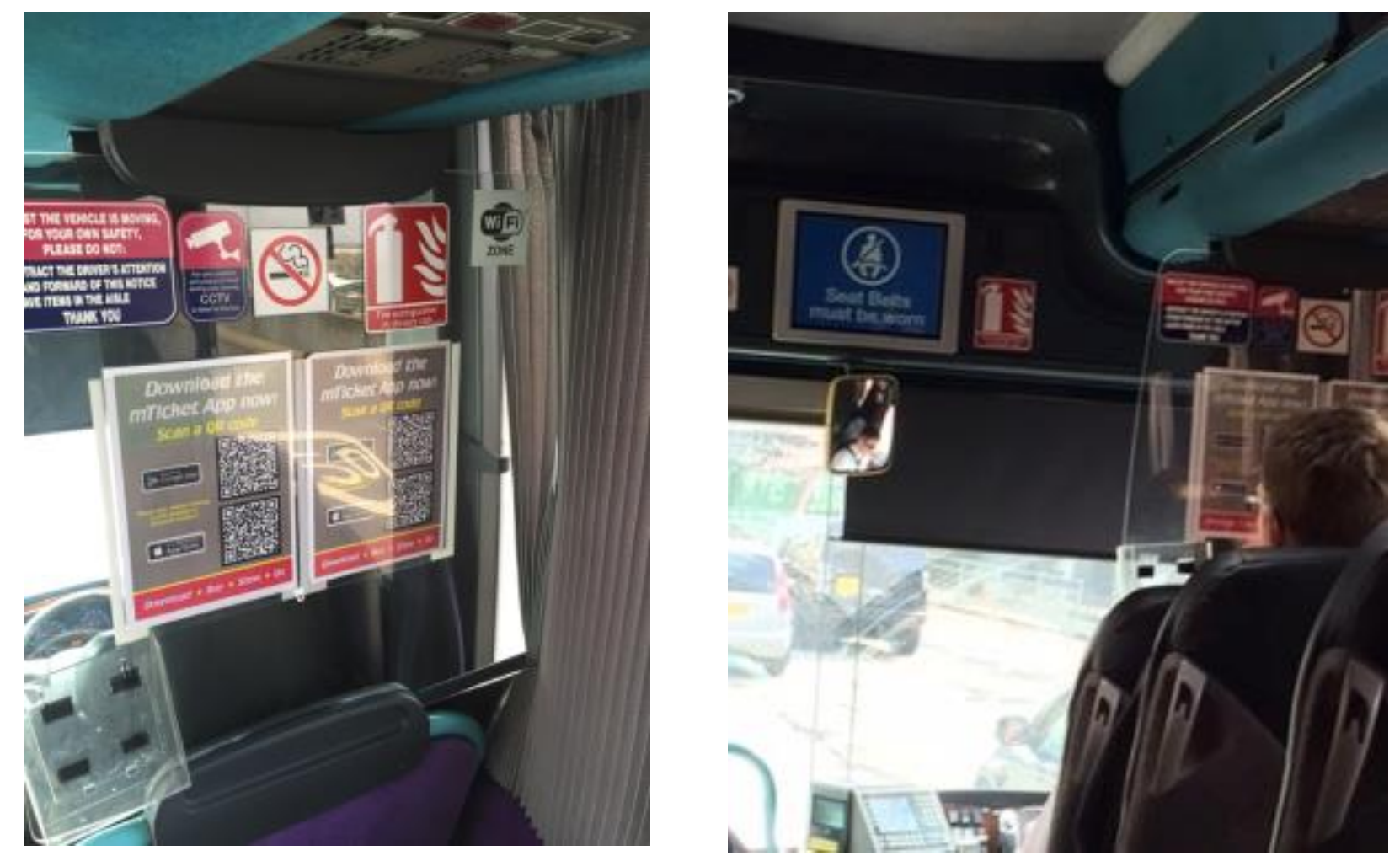

Figures 1.1 \& 1.2 On a bus from Reading, UK to Heathrow Airport

What this example highlights is the fact that what semiotic aspects of surveillant landscapes communicate to their inhabitants is often indirect or incomplete, sometimes designed to disguise the practice of surveillance as something intended to ensure the reader's comfort and well-being. Another thing it highlights is the interactive nature of surveillant landscapes, the fact that they almost always in some way depend for their operation on the participation of those who are being surveilled, whether it be in the form of compliance, or in the form of more active participation such as offering information, downloading apps, or by participating in surveillance themselves. In other words, inhabitants of surveillant landscapes are themselves part of the 'discourses in place'; by the presence of the surveillant gaze in the form of technologies like video cameras and rearview mirrors, their actions, such as not smoking or fastening their seat belts (or just being physically present) are made meaningful. Finally, this example reminds us that when we think about surveillant landscapes in terms of 'discourses in place', we must remember that the places we 
inhabit are often composed of complex layerings of physical and virtual spaces, and that many, if not most, surveillant landscapes involve the transmission of semiotic material across multiple spaces: whatever is happening on this bus for example, is presumably also occurring on some remote TV screen far from the interior of the bus, and passengers who have bought their tickets using the mTicket app will carry a record of this bus ride with them far beyond the confines of this vehicle.

In their classic book, Discourses in Place: Language in the material world (2003), Ron and Suzanne Scollon discuss two interrelated forms of semiosis that govern the way discourses in place communicate meaning when it comes to things like shop signs, traffic signs, and official notices: what they call 'visual semiotics', the aspect of meaning making that comes from the use of words, images, colors, fonts, and the deployment of certain kinds of physical objects or people (for example, uniformed security guards), and what they call 'place semiotics', the aspect of meaning making that comes from how these words, images, objects and people are emplaced in the physical environment and how they interact with that environment. Whereas the kind of meaning communicated through visual semiotics is chiefly semantic, the kind of meeting communicated through place semiotics is chiefly indexical.

This distinction between semantic and indexical meaning making is particularly useful when it comes to analyzing signs that announce the presence of surveillance cameras. In many places, such as Britain, such signs are mandated by law wherever a security camera is in use, and such laws often stipulate the information that must be included on the signs. In Britain, for example, signs must include 1) a clear statement that security cameras are in operation, 2) a statement of the identity of the person or organization responsible for the scheme, 3) the purpose for which the monitoring is being carried out, 4) contact details of the person or organization responsible. ${ }^{1}$ These

\footnotetext{
${ }^{1}$ Despite these legal requirements, many of the signs I encountered in Britain did not contain all of this information.
} 
requirements have resulted in a kind of template that is used on commercially available signs whose purchasers can fill-in their own information (see Figure 2).

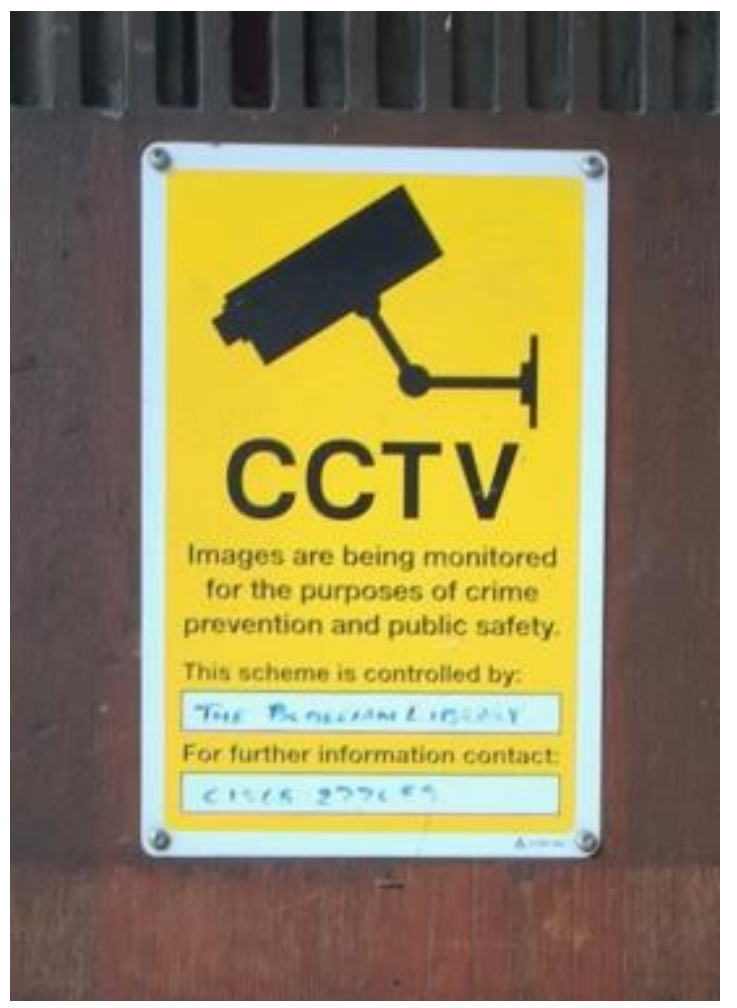

\section{Figure 2 Oxford, UK}

The way this information is arranged on signs, however, can vary depending on what aspect of the message the people or organizations responsible wish to highlight. One way to highlight a particular aspect of the message is to use the grammatical resource of thematization (Halliday and Matthiesson, 2014), placing a particular piece of information in the initial position of the clause in order to give it the status of the 'topic' or 'given information'. Surveillance camera signs, for example, can thematize the camera itself ('CCTV in operation', 'Video cameras are in operation'), what the cameras are recording ('Images are being recorded 24 hours a day'), the area or premises that is under surveillance ('This property is protected by video surveillance'), the purpose of the surveillance ('For your added safety and security...', 'For the purposes of crime prevention...'), the person or organization conducting the surveillance ('University of Reading operates CCTV cameras on this campus', 'We've got our eye on criminals'), or the person or type of person being surveilled 
('Criminals beware', 'You are on camera!'). Sometimes what is the thematized is some kind of metalanguage which describes the nature of the message below it ('Security Notice', 'Warning', 'Polite Notice'). Of the 264 photos in my data set of signs related to security cameras, the most popular themes were the cameras themselves (36\%), the premises under surveillance (18\%), and the person or type of person being surveilled such as criminals or trespassers $(8 \%)$. The least common theme was the person or organization that was carrying out the surveillance. This is not to say that people and organizations carrying out video surveillance typically downplay their own identities on surveillance signs. In some cases, other means such as color or typography are used to make the identity of the person or scheme prominent. In Figure 3, for example, while 'CCTV' is thematized, the most prominent element in the sign is the graphic in the center announcing the name of the scheme ('Westminster CCTV'), and communicating the purpose of the scheme in terms of a verbal attribute ('Making our streets safer'), as if the purpose of the sign is as much to promote the scheme as it is to warn of the presence of surveillance cameras. Similarly, Figure 4 highlights the name of the security firm ('H\&M Security') responsible for the surveillance, as well as the firm's phone number, so that this sign, while complying with regulations stipulating that passersby must be warned that surveillance is taking place, functions just as much as an advertisement for the company carrying out the surveillance. 


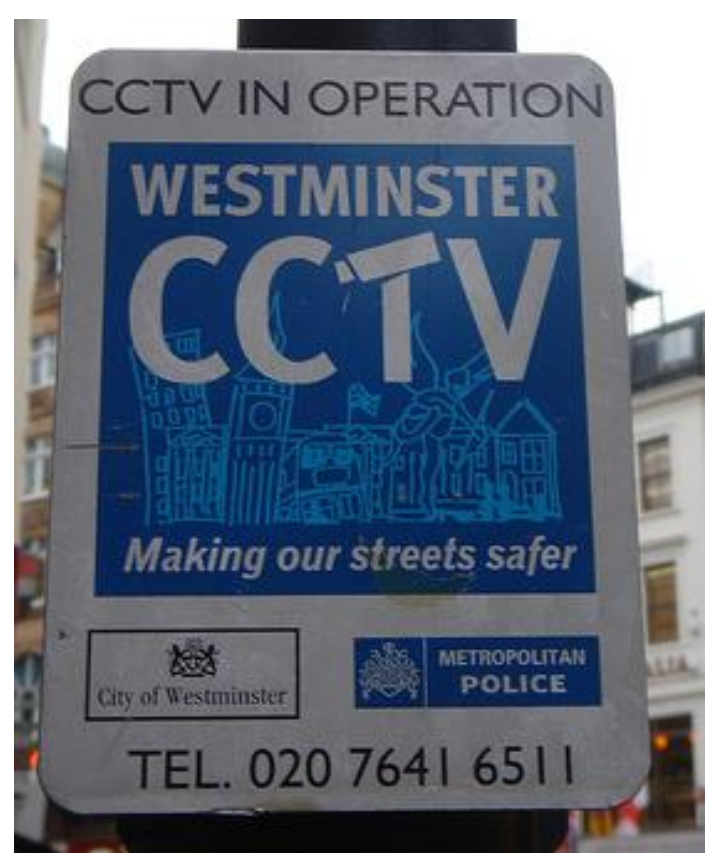

Figure 3 London, UK

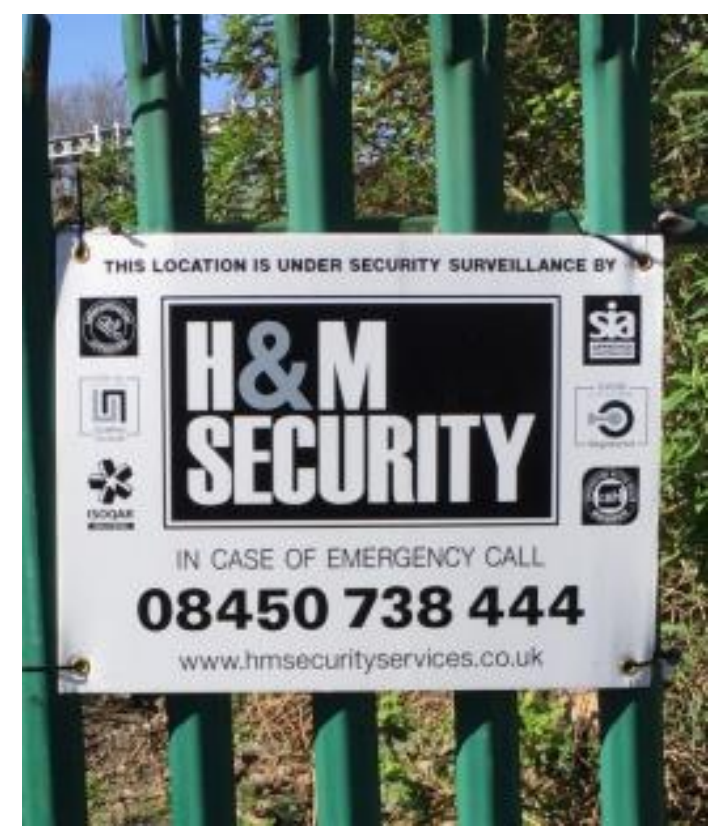

Figure 4 Reading, UK

Of course, the main way the presence of security cameras is communicated on such signs is usually visual rather than verbal - through a picture on a video camera, which by now has become fairly conventionalized as a black rectangle mounted on a wall, inevitably pointing downward, perhaps to communicate the fact that surveillance comes from above (the word comes from the French sur'over' + veiller 'watch') (see Figures 5 and 6). But cameras are not the only images that communicate surveillance; sometimes it is expressed through eyes looking out from the signs, presumably representing the eyes of those who are watching, as in Figure 7, in which a blue-eye represents the neighborhood watch in a suburban US neighborhood. 

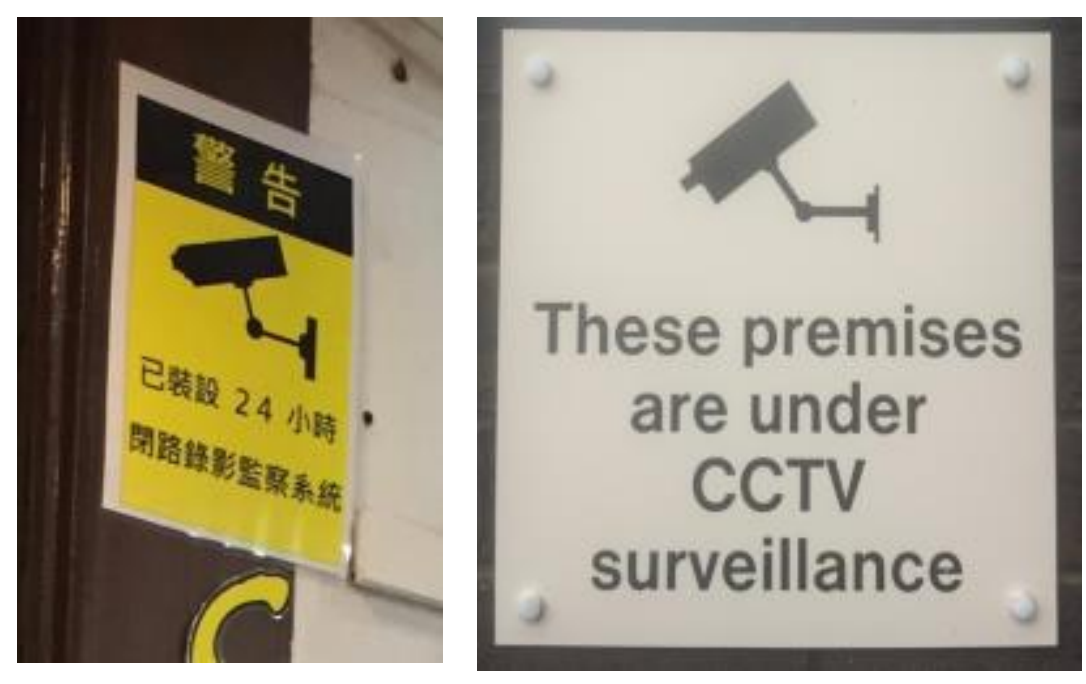

Figure 5 Hong Kong
Figure 6 Reading, UK

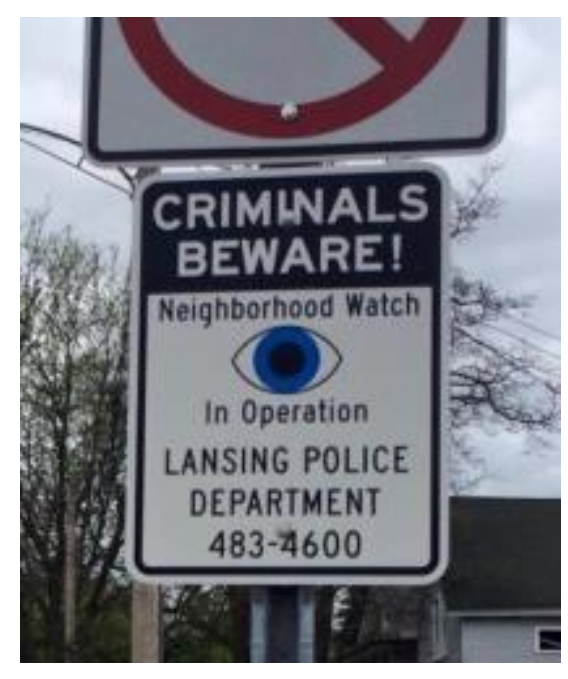

Figure 7 Lansing, MI, USA

(photo credit: David Malinowski)

Sometimes different visual elements are combined to form a kind of narrative, as in figure 8 , in which a security camera is trained on an unhappy looking emoticon, and Figure 9, in which the camera, the object of surveillance (a car), and the agent of surveillance (a police officer) are arranged in a particular relationship to one another.

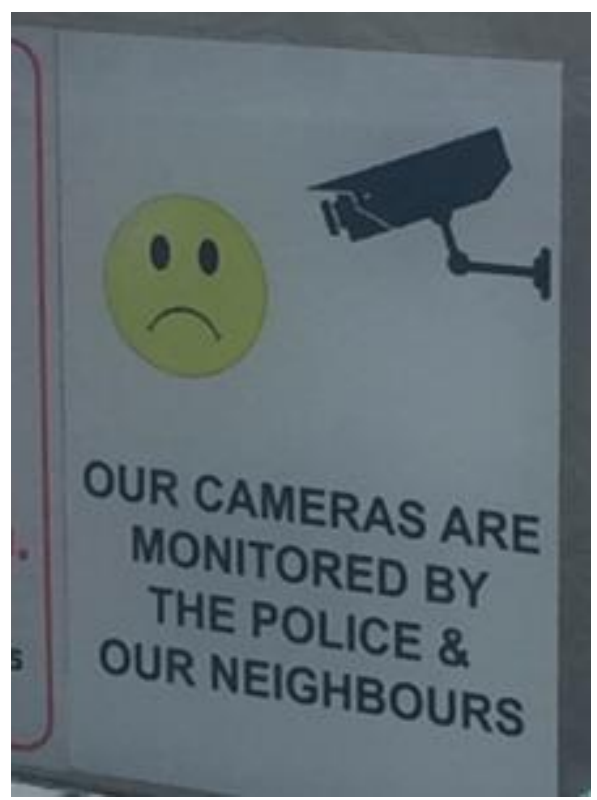

Figure 8 Brighton, UK

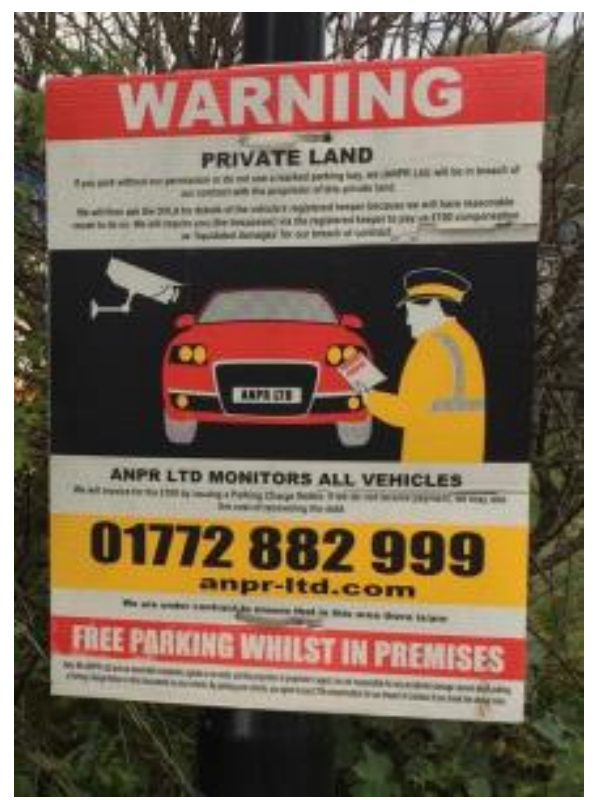

Figure 9, Reading, UK 
As I said above, however, as with most signs, the meaning of surveillance signs depends not just on the visual and verbal semiotics inscribed on the sign, but also on the way the sign is emplaced in and interacts with the physical environment. The most obvious aspect of indexical meaning has to do with the identification of the place in which surveillance is taking place, as in Figure 10, in which the sign in a shop is strategically placed next to small items which might present a temptation to shoplifters. Another important aspect of the physical placement of signs has to do with their relationship to the actual physical cameras to which they refer. Sometimes the placement of the camera is close enough to the sign so that the indexical relationship is clear, as in Figure 11, in which the camera is mounted on the wall right next to the sign announcing its presence.

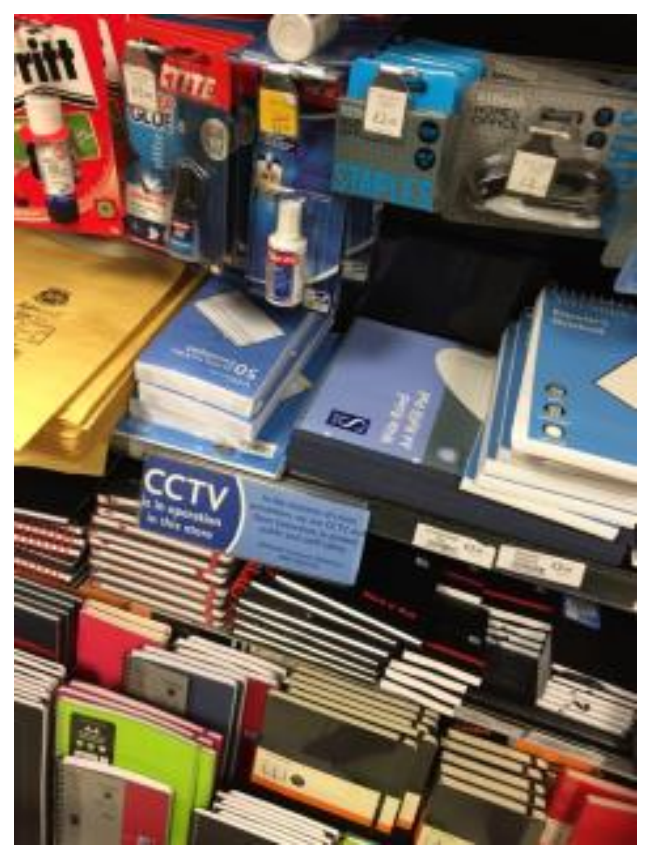

Figure 10 Reading, UK

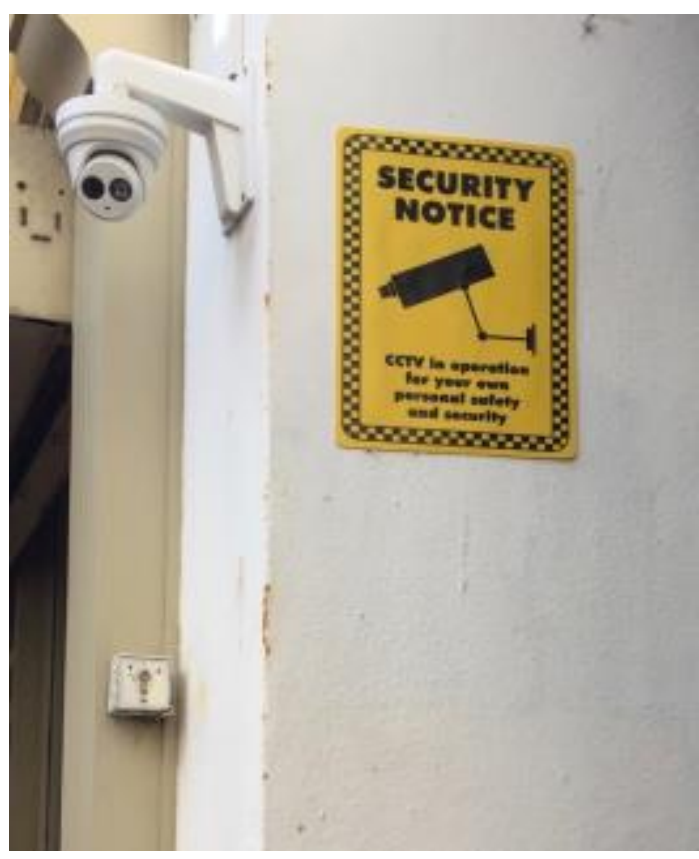

Figure 11 London, UK

Sometimes, however, the actual camera to which the sign is referring is difficult to locate, as in the sign pictured in Figure 12, which is placed in the middle a large field next to the Thames River, with no obvious structure in sight on which the camera might be mounted, and sometimes the sign makes it clear that it refers not to one but to multiple devices and that surveillance is not limited to 
any clearly defined area, as in Figure 13, which indicates the presence of cameras on the campus but does not say where they are. The indexical meaning created by the emplacement of signs in relation to actual cameras, therefore, can either communicate verifiability ('there is the camera right there'), or unverifiablity (be careful, there's a camera here somewhere'), and, as in Foucault's panopticon, it is unverifiability that is likely the most effective tool for disciplining the objects of surveillance.

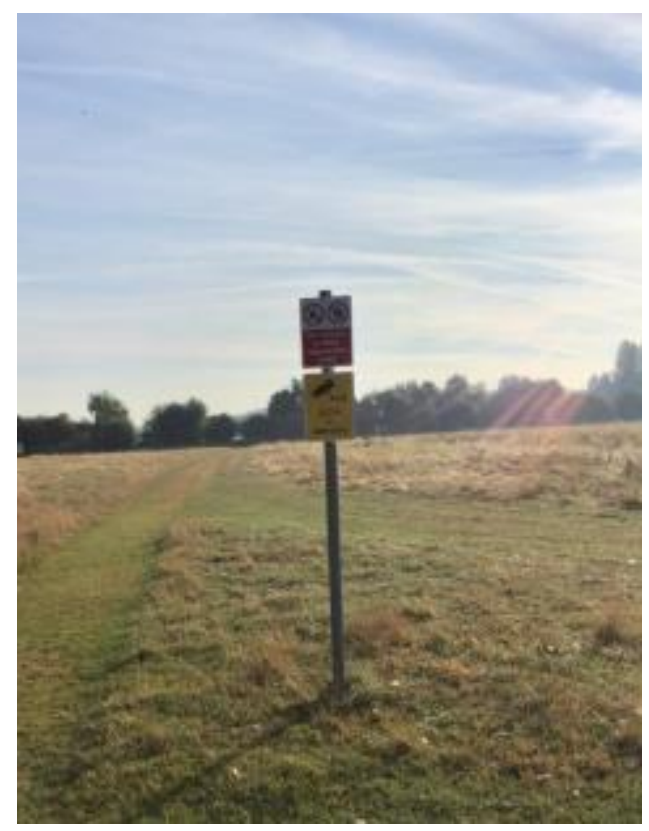

Figure 12 Reading, UK

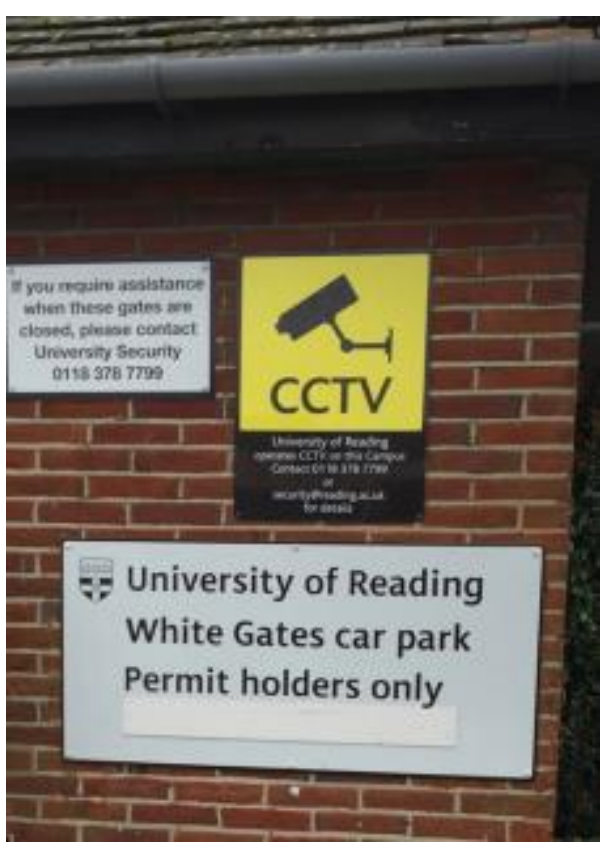

Figure 13 Reading, UK

Where cameras are visible, however an important aspect of the indexical meaning they express comes from the direction in which they are literally pointing. In Figure 14, for example, the camera is placed conspicuously at the entrance of the building, communicating that it is monitoring whoever enters or leaves, and in Figure 15 of a currency exchange booth at Hong Kong International Airport, the cameras are conspicuously pointed at the cashier, communicating to customers that their transactions are being monitored (and to the cashier that she is being watched). Sometimes, however, the picture of a camera on a sign can communicate the same kind of indexical 
meaning, as in Figure 16, in which the camera icon points at the entrance to a school, though the camera itself is out of sight.

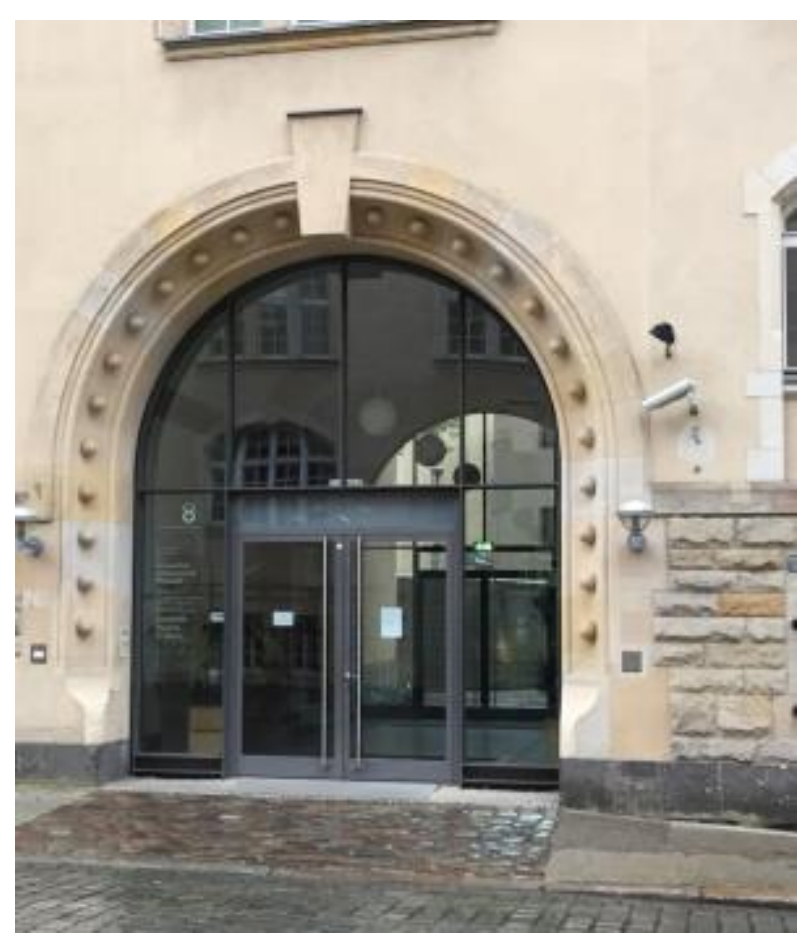

Figure 14 Berlin, Germany

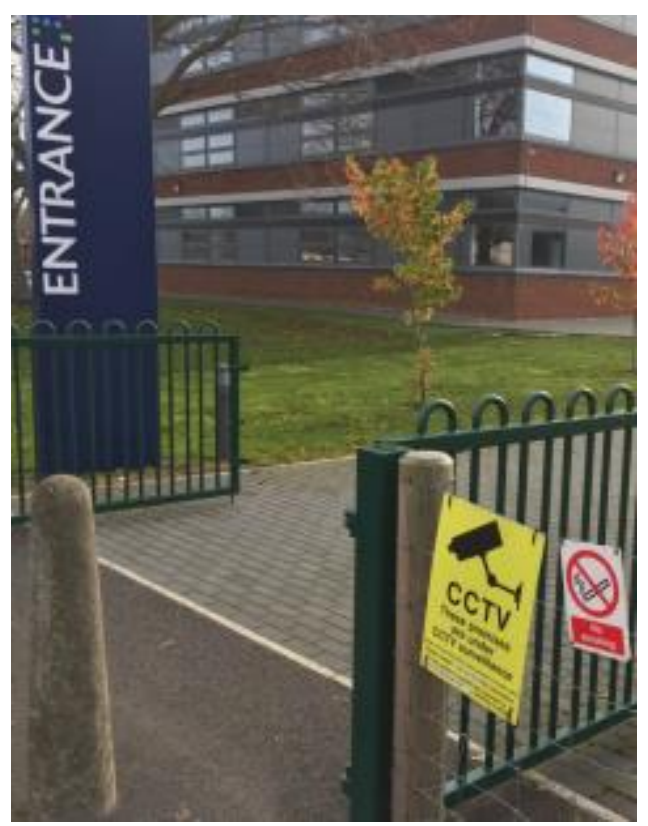

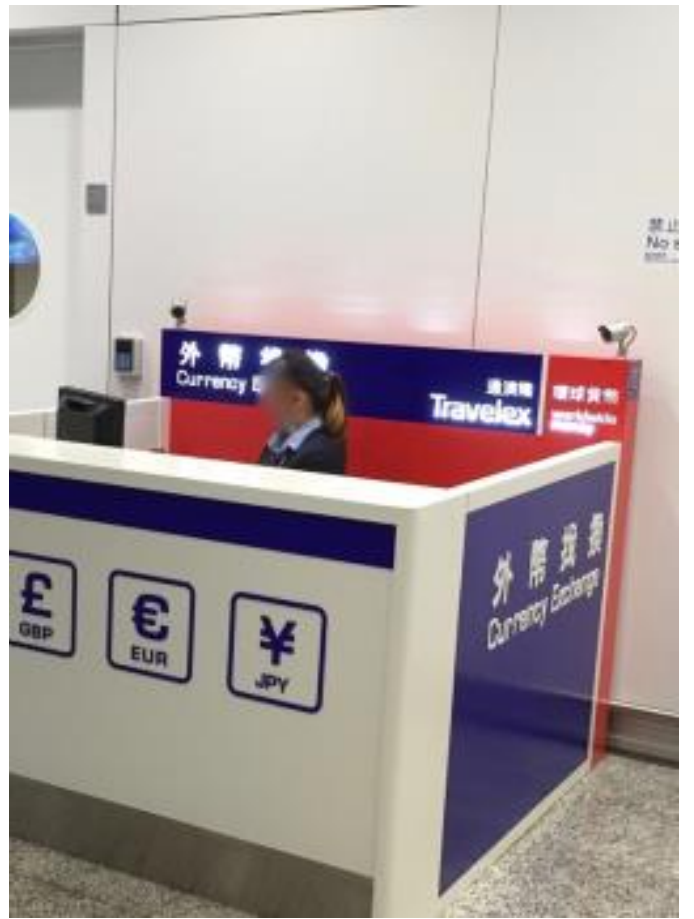

Figure 15 Hong Kong

Figure 16, Reading, UK 
Still another way emplacement helps to create meaning involves the proximity of surveillance signs to other signs, typically prohibitions on activities such as smoking, parking, and trespassing. As in the example in the beginning but this section (Figure 1.1), surveillance signs often operate as parts of 'semiotic aggregates', with their meaning dependent on or contributing to the meanings of other signs they are combined with. In Figure 17, for example, from a men's toilet in Paddington Station, the surveillance sign is placed next to a sign reminding users to pay 30p to use the facilities, with the lens of the camera pointing directly at the words 'pay at turnstile'. In other cases, however, the information alerting people to the presence of surveillance cameras it is more tightly integrated into other signs or into the surrounding environment in more inconspicuous ways, as if the warning regarding the presence of surveillance cameras is meant to blend in with surrounding commercial discourse: In Figure 18, for example, from the window of a convenience store, 'CCTV in operation' appears in a list of items for sale (wine, cigarettes, soft drinks), all written in the same font.

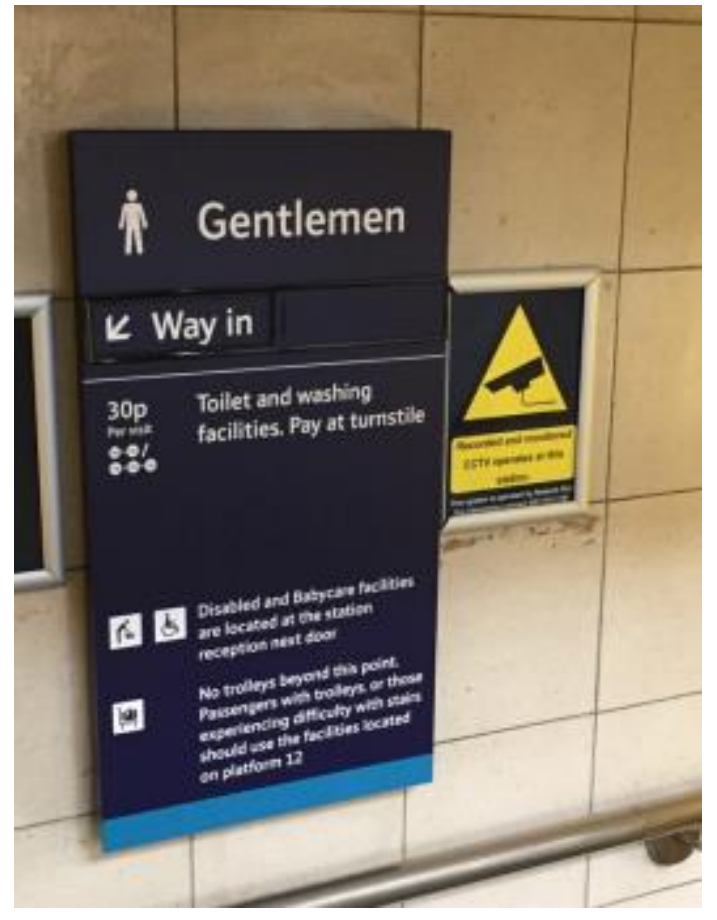

Figure 17 London, UK

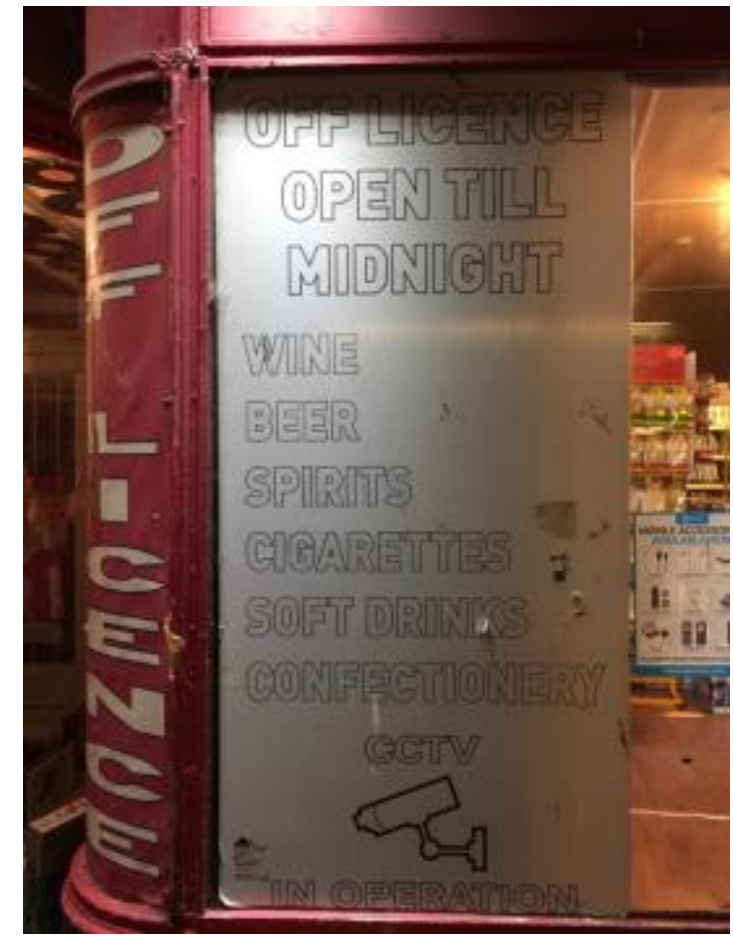

Figure 18 Brighton, UK 
And so, when considering the meanings surveillance cameras and the signs that announce their operation communicate, it is usually not enough just to look at what is written on the sign. Perhaps more than any other elements in semiotic landscapes, surveillance signs and equipment depend for their meaning on the way they are emplaced in and interact with particular elements of the environment: the particular space in which they appear - the character of which fundamentally changes through the presence of the surveillance camera - the other signs that are placed around it, and even the inhabitants of these environments and the way the architecture or layout of furniture positions them in relation to the cameras or signs - with for example, (as in Figure 15) cameras pointing at certain people rather than at others.

CCTV cameras, of course, are not the only technologies that transform places into surveillant landscapes. There are other aspects of built environments as well that communicate surveillance, and like cameras, these operate both through visual semiotics, and through their emplacement in particular material environments. Examples include street lamps, glass office partitions, 'obligatory passage points' (Graham, 2005) fitted with turnstiles or guarded by security guards, and the arrangement of desks in examination halls: all instances in which the architectural technology or physical arrangement of people serves to communicate the potential for inhabitants to be objects of surveillance. The invigilator who paces the rows of desks in an examination hall, like a surveillance camera, does not just accomplish the action of surveillance but also accomplishes the action of communicating to the students in the hall that they are being watched.

Even individuals less powerful than security guards or invigilators can communicate the surveillant potential of the environments that they inhabit through the way they situate themselves in or move through them, or through the deployment of objects like flashlights, whistles or telephones. Katz (2006), for example, found that female university students often pretend to talk on their mobile 
phones when walking home alone late at night as a signal to potential attackers that they are in contact with someone who can help.

Some surveillant landscapes, however, are designed so that the watcher is no longer necessary - the physical features of the architecture perform the work of preventing particular kinds of behavior or excluding particular kinds of people. Tony Monahan (2006) calls the features of built objects that program spaces for certain uses and exclude other uses 'surveillance architectures', but what is most striking about these architectures is that they make the ongoing practice of surveillance unnecessary - surveillance takes the status of what Norris (2004) calls a 'frozen action', a feature of the environment that marks it as a place in which the 'solution' to the 'problem' of surveillance has been built into the brick-and-mortar. The spikes on the ledge outside a shop in Berlin in Figure 19 both communicate the fact that sitting or sleeping is not allowed on this space and also makes such activities extremely uncomfortable if not impossible.

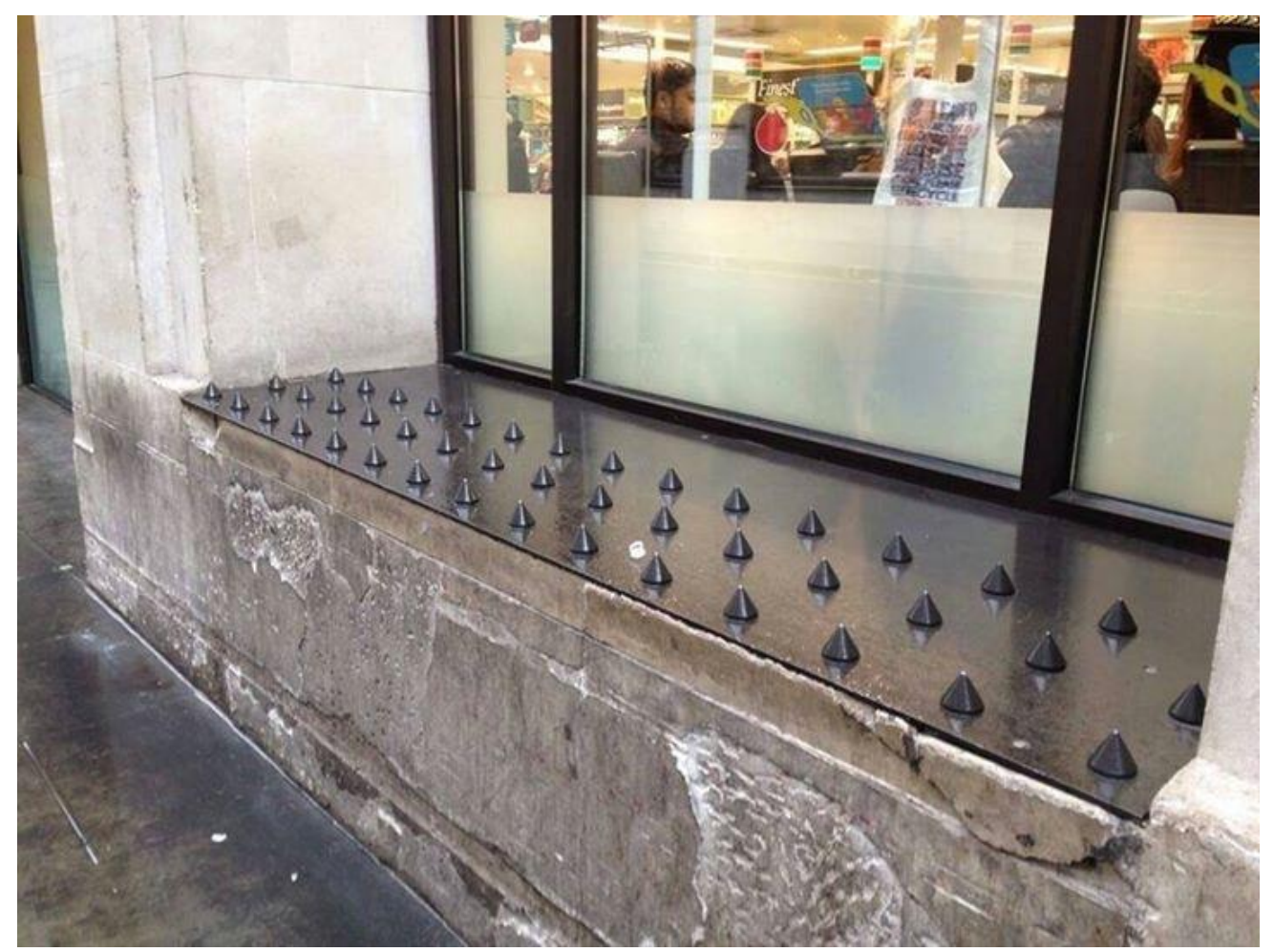

Figure 19, Berlin, Germany 


\section{Interaction Orders}

When I speak of the 'interaction orders' in relation to surveillant landscapes, I am referring to the ways material and semiotic aspects of environments work to create certain kinds of relationships between the watcher and the watched, how they help to enforce particular power relations and particular sets of rights and responsibilities, and how they position different people in different ways (as for example, innocent, suspicious, desirable, or undesirable). The term was coined by Goffman (1983), for whom a key element of social life was how people use the 'expressive equipment' available to them to reveal or conceal certain aspects of themselves and to gather information about others. For Goffman, surveillance forms an integral part of all social interactions: social situations are essentially defined as 'environments of mutual monitoring possibilities' (1964:135), and in his work he explored how people divide these environments into 'front stage' and 'backstage' areas (1959), and how they make use of 'involvement shields' (1963) in order to block the perception of certain activities. In Goffmanian terms, then, interaction orders refer to the kinds of 'social situations' that built environments help to make possible, including the possibilities for 'mutual monitoring' they make available, and the way they facilitate certain kinds of 'performances'.

The way different kinds of built environments help to create particular relationships was also a preoccupation for Foucault, but for Foucault the important thing was not just how particular kinds of interaction and particular social relationships are enforced by surveillant architectures, but also how these architectures and interactions reinforce unequal relations of power. For Foucault, the forms of visibility and monitoring made possible by panoptic structures such as prisons, clinics, and classrooms operate, first, by enforcing certain forms of social organization, separating, for example, guards from prisoners and segregating prisoners from one another, and second by categorizing or defining those within these social structures in terms of particular roles or identities, what Foucault (1970: 132) called 'the nomination of the visible.' Drawing on Foucault, Nicholas Mirzoeff (2011) 
points out another function of surveillant architectures, what he calls their 'aesthetic' function, the way they operate to make the unequal power relationships they enforce seem 'right', 'just' or even 'pleasurable'. In the example of the airport currency exchange counter pictured in Figure 15, for example, the training of the surveillance cameras on the employee separates her from the customer and classifies her as the person needing to be watched. Presumably the intended effect of this order of interaction is to make the customer feel secure about the transaction as well as to keep the employee 'honest'. But at the same time the interaction order created here also reinforces broader notions of how employers should be able to treat their employees. In other words, the situated interaction orders constructed by surveillant landscapes often act to invoke and reinforce broader cultural narratives about certain kinds of people and the kinds of relationships they are supposed to have: people such as employers and employees, shopkeepers and customers, criminals and victims, terrorists and their potential targets, and citizens and their governments.

From a linguistic point of view, one way to understand how surveillant landscapes construct and maintain orders of interaction is through attention to how interpersonal resources for meaning making (Halliday and Matthiessen, 2014) are deployed. Such resources include aspects of grammar such as mood, modality, and the use of pronouns, as well as discourse level features such as registers, genres, politeness strategies and forms of address. Such tools can be used on surveillance signs, for example, to construct the social identities of watchers and those who are being watched and the relationship between them. In Figure 20, for example, the identity of the security company conducting the surveillance is constructed through the use of a militaristic register with words like 'covert devices', 'thermal imaging' and 'deployed'. In Figure 21, however, the watcher is identified as the 'community', a group to which which readers themselves may be able to claim membership. Both of these strategies serve the purpose of claiming for the watcher, and for the practice of watching, a certain form of legitimacy based on who the watchers are. On some signs, however, the identity of the watcher is backgrounded, and the legitimacy of the practice of watching is claimed 
through more impersonal, circumstantial means, as in the sign pictured in Figure 22, in which the information that surveillance is being carried out by Mitchells and Butlers Leisure Retail Ltd is buried in the 'fine print' of what appears to be the register of a legal document; the watcher here is neither a threatening authority figure nor a member of the 'community', but rather the administrative agent of a faceless bureaucracy, and the relationship between the watcher and the watched is construed as legalistic and contractual.

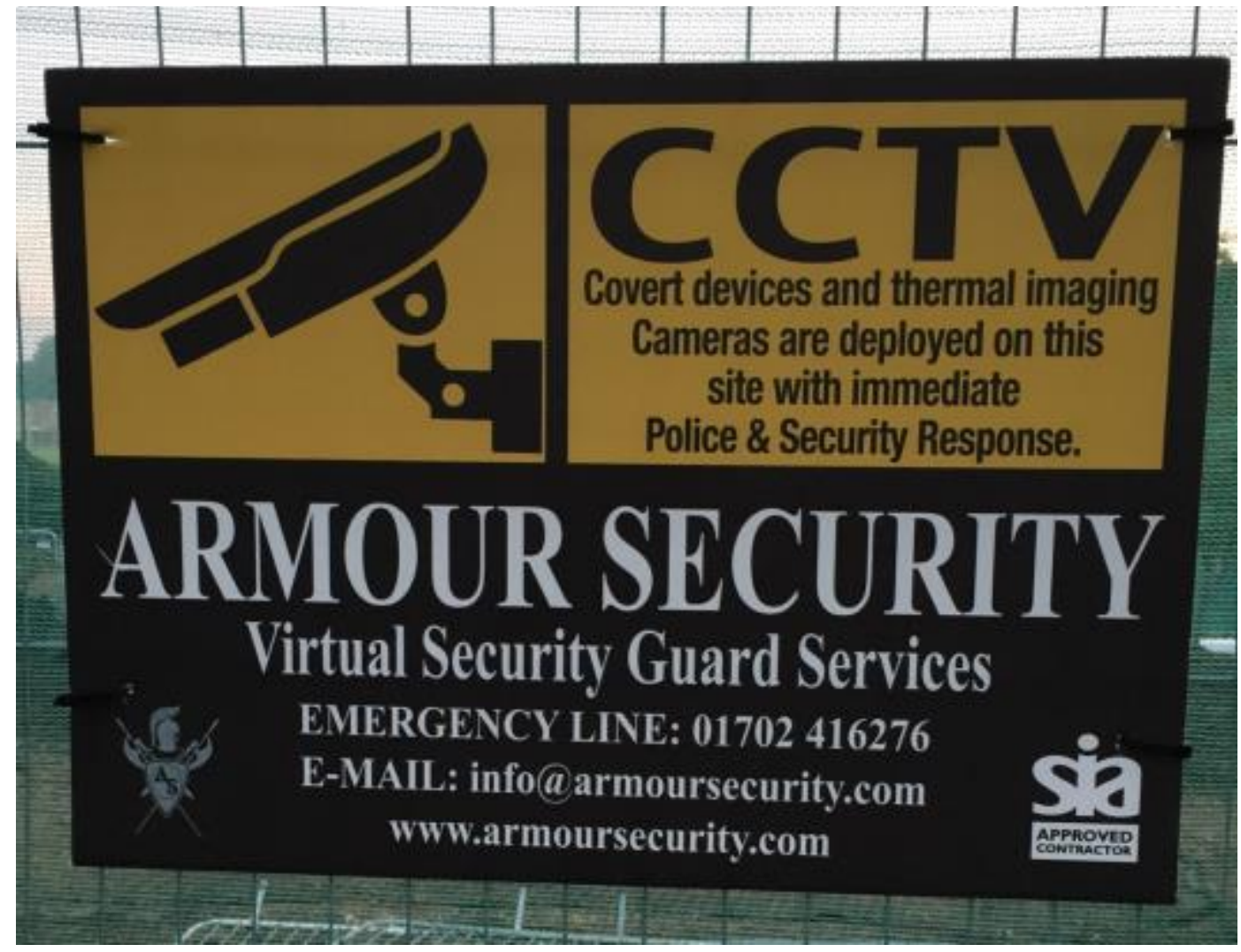

Figure 20, Reading, UK 


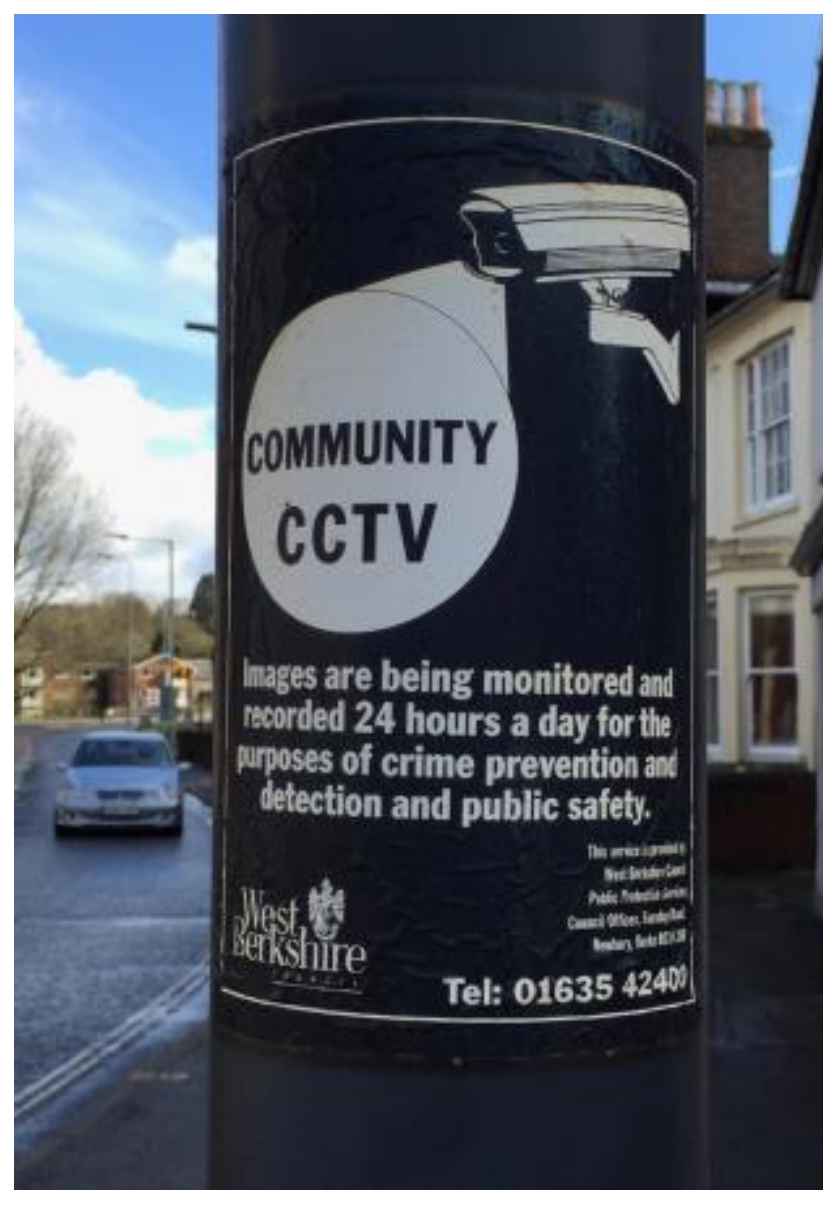

Figure 21, Hungerford, UK

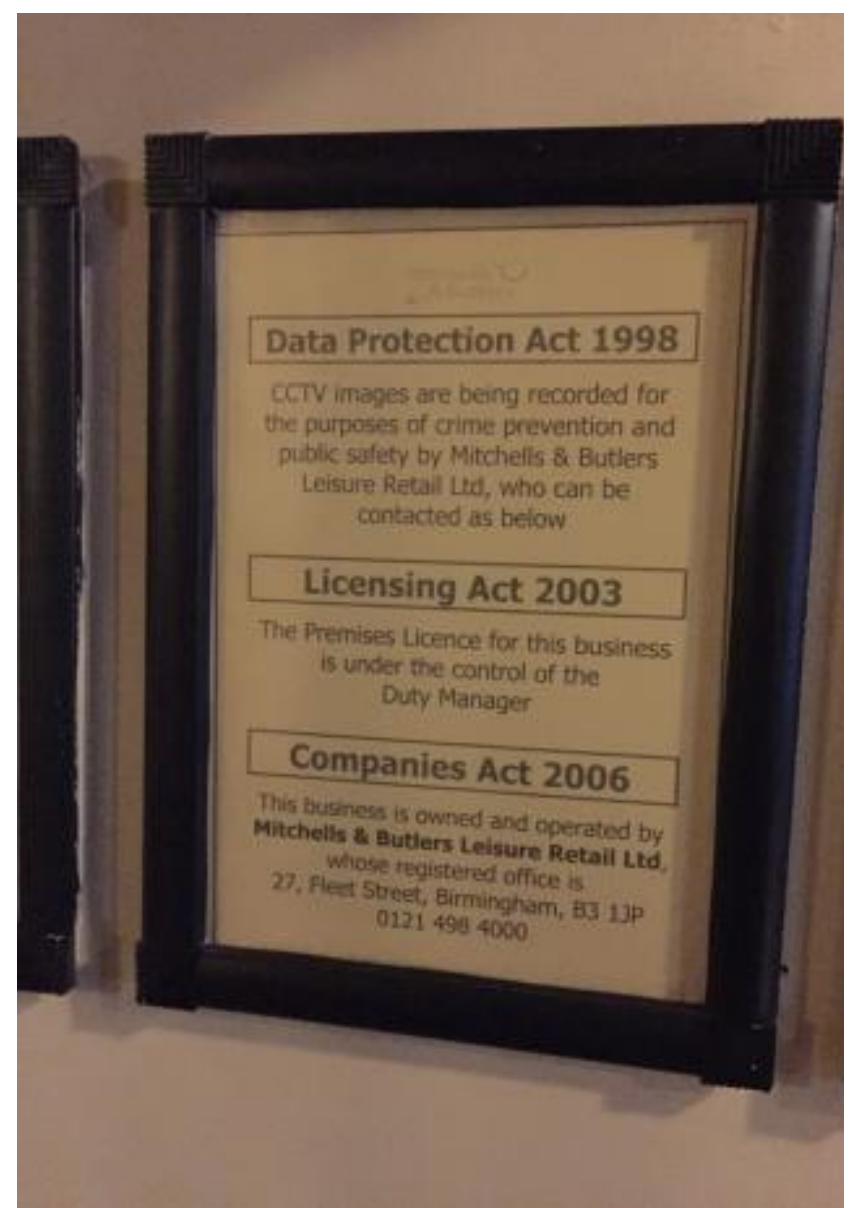

Figure 22, London, UK

The way surveillance signs construct interaction orders is even clearer in the way they use interpersonal resources for meaning making to address their readers and to impute upon them particular identities or intentions. Often, surveillance signs directly address those who might carry out the very behavior they are designed to prevent, as in Figure 7 (above) which directly addresses potential criminals with the words 'Criminals Beware'. In cases such as this, social identities are constructed through a process of what Althusser (2008) called 'interpellation', potential criminals are 'hailed' in the same way they are in Althusser's famous example of a cop shouting, 'Hey you there!'. Other signs hail their subject in more conspiratorial ways, constructing them not as criminals but as the beneficiaries of surveillance, as in the sign on the bus in Figure 1.1, which explains to the reader that CCTV cameras are fitted on the bus for their 'comfort and peace of mind 
during (their) journey'. Of course, the main point Althusser makes about these acts of hailing is that, whether they construct the subjects as criminals or as law-abiding citizens, they function to reproduce broader ideologies and power relationships on the level of each individual interaction in which they occur: whether passengers on the bus take the presence of the CCTV camera as a reason to avoid engaging in prohibited activities like smoking or as a reason to feel more comfortable and secure during their journey, they are being complicit in reproducing the relationship of power between them and the bus company, and of reproducing the the idea that surveillance is a good thing.

The interpellative nature of surveillance signs, and the inevitable ambiguity it entails, however, presents a problem for the composition of 'efficient' surveillant landscapes: in most cases, particularly in commercial settings, surveillance signs must simultaneously address both the objects of surveillance and the beneficiaries of it, or, to put another way, they must construct their readers simultaneously as potential criminals and as potential victims. This sometimes results in a kind of multivoicedness in which language that addresses readers in friendly, comforting terms is juxtaposed with the language of threat or accusation. In Figure 23, for example, from a supermarket chain in Britain, different kinds of readers are constructed: 'customers and colleagues', whose 'safety' is the reason surveillance is being carried out, and 'shoplifters', who face the threat of prosecution, with the result that the 'you' in the sentence 'Sainsbury's is looking out for you', as well as the meaning of the verb phrase 'looking out for', take on double meanings. 


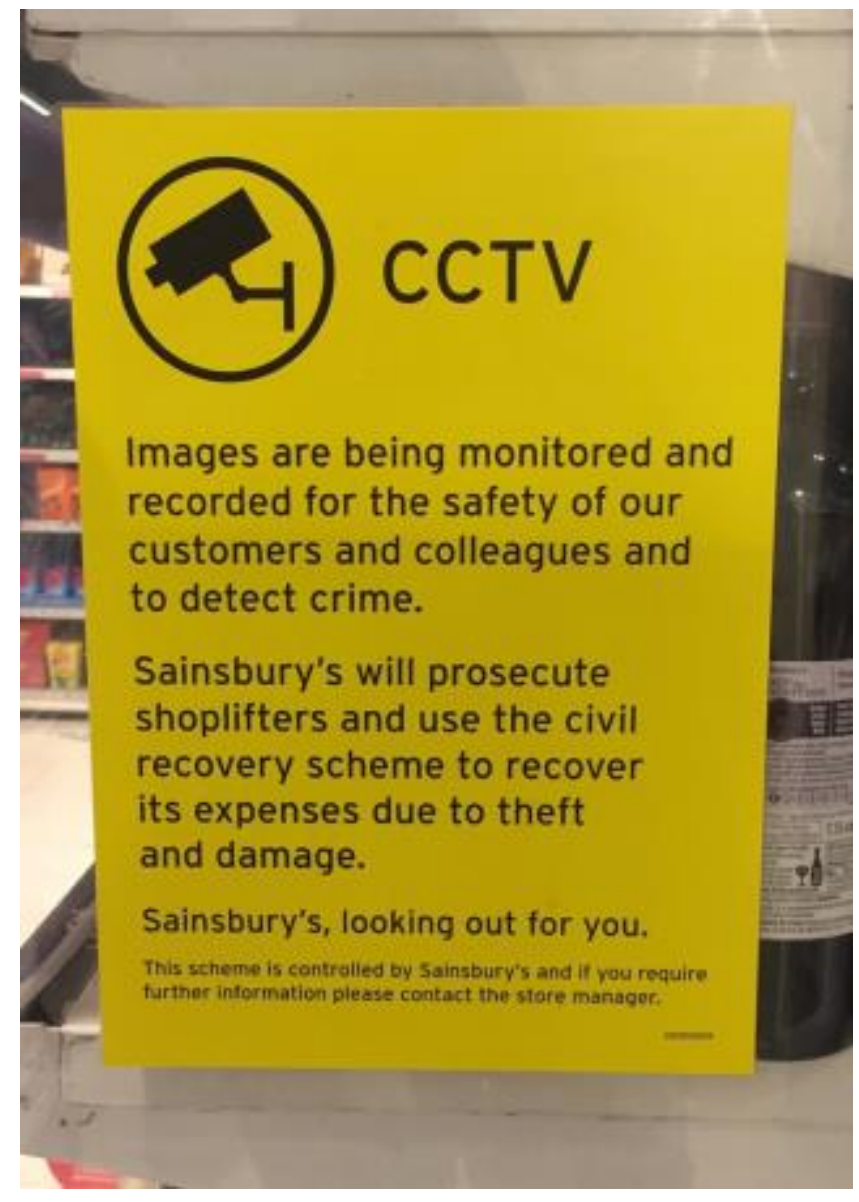

Figure 23, Reading, UK

Often it is important for authors of surveillance signs to preserve the 'face' of their customers by mitigating the imputation of the negative identity of a potential wrongdoer. In a sign posted in an antique shop in Hungerford, UK, pictured in Figure 24, the customer is hailed respectfully with a 'polite notice', and a request ('Please ensure that all items are paid for'), and 'thieves' are addressed indirectly by being talked about in the third person. Sometimes commercial establishments address the dilemma of having to warn customers about surveillance without seeming to accuse them of wrongdoing through humor or irony, instructing them, to 'smile' for surveillance cameras, for example, or, as in Figure 25, from a high-end hotel in Reading, UK, to 'strike a pose', invoking what Mirzoeff calls the 'aesthetic' dimension of surveillance. 


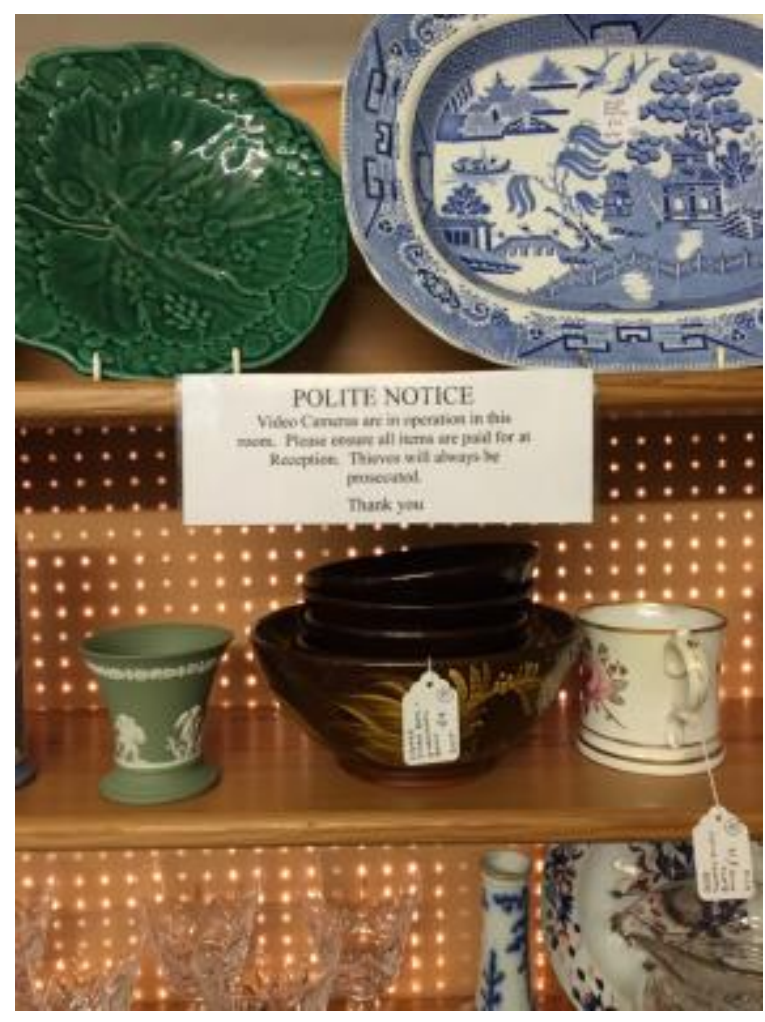

Figure 24, Hungerford, UK

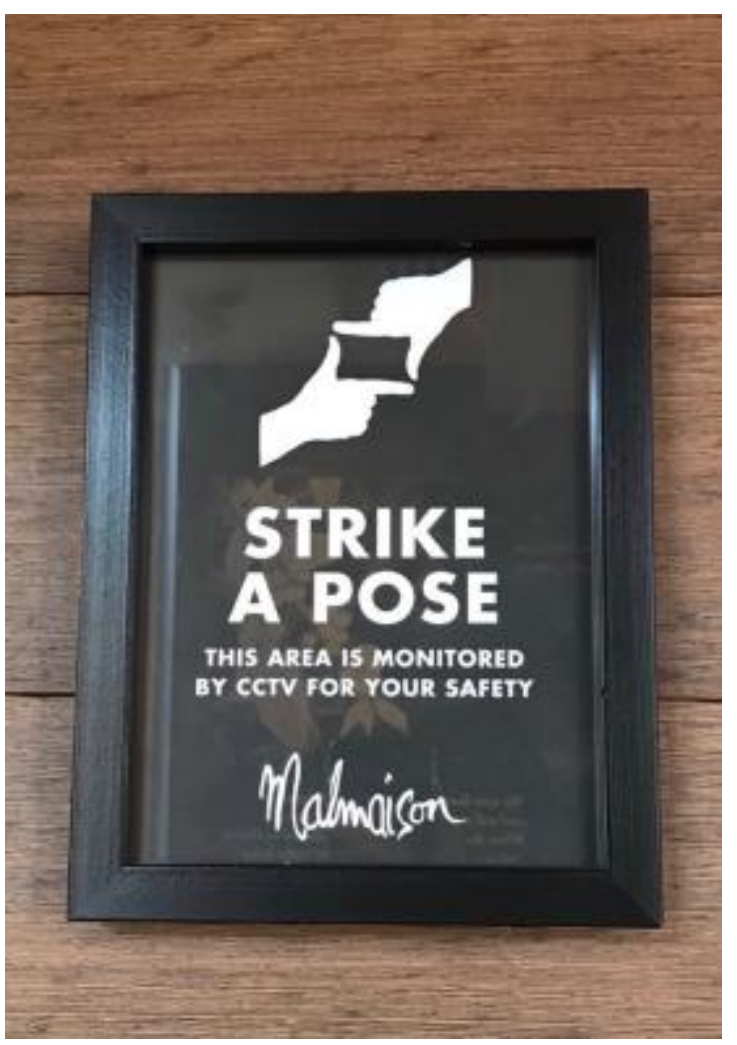

Figure 25, Reading, UK

Another way surveillance relationships are made aesthetic is by rendering the acts of interpellation that surveillant landscapes engage in invisible to those towards whom they are not directed. The 'skate stoppers' pictured in figure 26 are likely only recognizable as exclusionary signs to skateboarders; for others they appear simply as decorative and inviting features of the urban landscape. These examples highlight the fact that in modern consumer societies one of the main purposes of surveillance cameras and signs and other features of the urban architecture is to construct identities of neoliberal citizens/consumers for whom surveillance is construed not as a matter of subservience or coercion but as a matter of 'freedom' and 'empowerment', especially, as Coleman and Sim (2000:635) put it, 'the freedom and safety to shop'. The purpose of surveillance is not just to prevent certain things from happening but, as Amin and Thrift (2002:81) put it, to 'engineer encounters', including encounters involving civic and commercial transactions. Of course, through engineering such encounters, they inevitably contribute to the engineering of 
relationships of inequality, separating some inhabitants from others and classifying them as undesirable, unproductive, or dangerous.

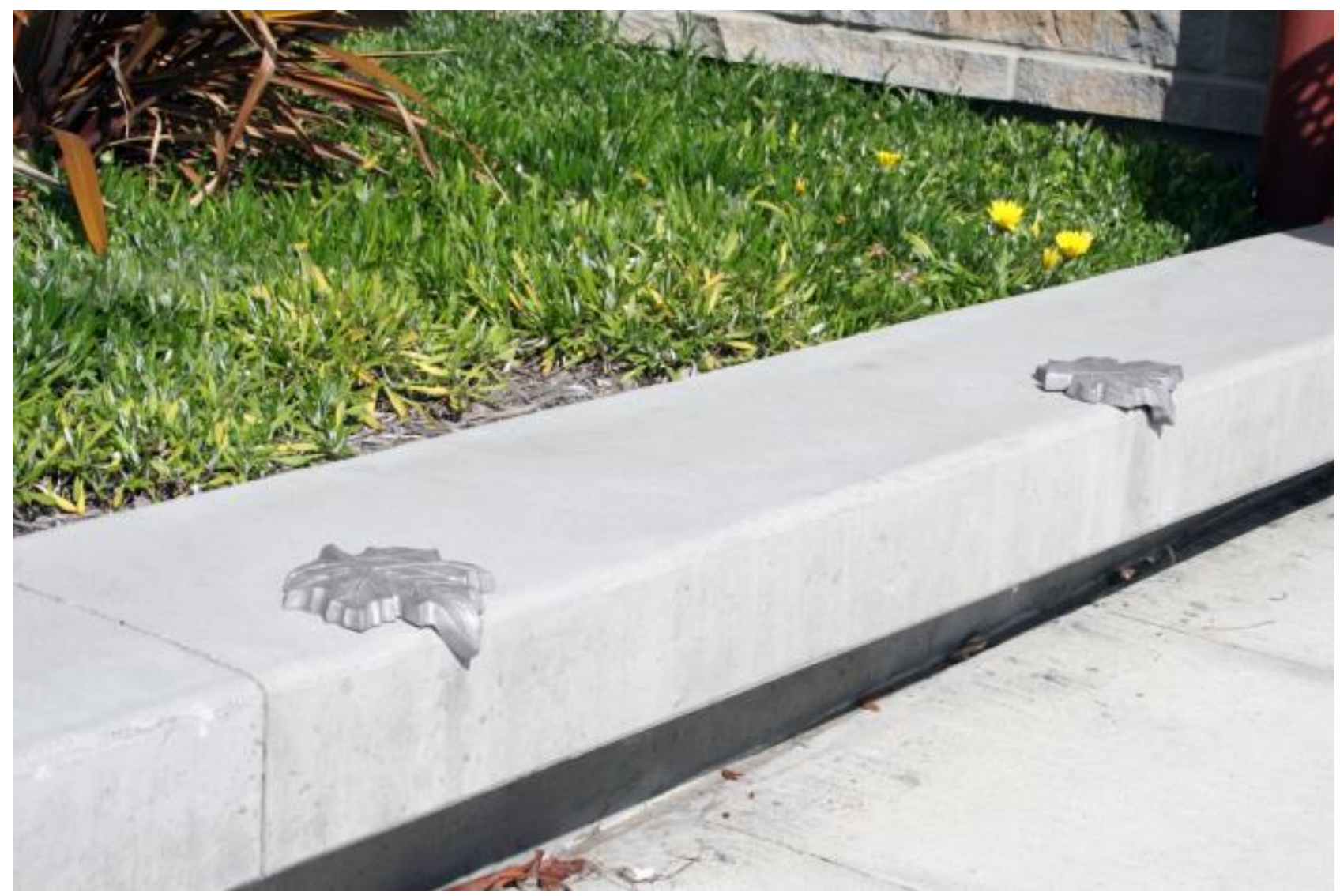

Figure 27, San Diego, CA, USA

In some cases inhabitants of surveillant landscapes are not just constructed as innocent bystanders or fortunate beneficiaries, but are actually recruited into the practice of surveillance themselves, asked to take on the role of watchers. This is particularly true of signs intended to help prevent acts of terrorism; the purpose of such signs is not just to construct the reader as 'law-abiding', but also to construct a 'dangerous other'. After 9/11, for example, signs with the slogan 'If you see something, say something' appeared in public places like railway stations and airports throughout the US. Figure 27, from a London Underground train, instructs readers to 'Trust (their) senses', as opposed to trusting the people around them. In such cases, not just being complicit in, but becoming an active agent in state surveillance becomes a marker of of citizenship. At the same time, not all forms of citizen surveillance are sanctioned. Figure 28, also from the London Underground, 
instructs readers to keep an eye out for people taking pictures. This example highlights another important aspect of interaction orders, the fact that the different roles and relationships of visibility that surveillant landscapes enforce also involve different 'rights to look'. States and institutions exercise power, says Mirzoeff (2011), not just through engaging in surveillance, but also through controlling who else has the authority to do so, through controlling who has 'the right to look'.

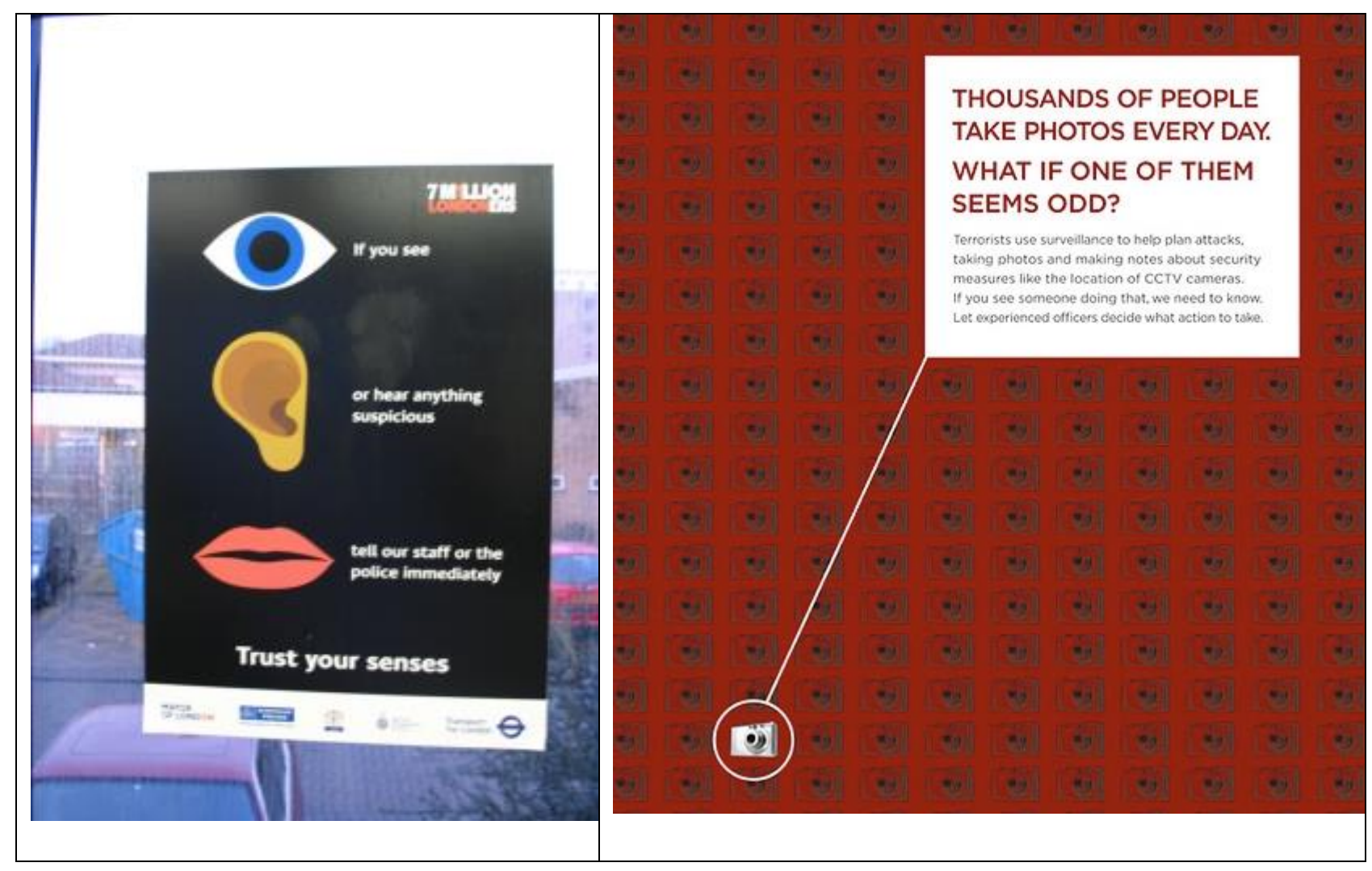

Figure 27, London

Figure 28, London

Of course, with the advent of mobile phones, and new practices of citizens recording the behavior of authority figures, this form of control is breaking down, destabilizing interaction orders between, for example, police officers and protesters (see for example Jones and Li 2017), and creating what Wall and Linneman (2014:133) call 'practical struggles over the authority and regulation of ways of looking and knowing.' This shift can be seen not just in videos of police encounters published on YouTube, but also in citizen produced surveillance signs, such as the one pictured in Figure 29 from the 2014 Umbrella Movement protests in Hong Kong, warning the government that it is being 
watched, and in guerrilla tactics like those engaged in by the Surveillance Camera Players, a group which enacts dramatic performances including adaptations of George Orwell's Nineteen-Eighty-

Four and Wilhelm Reich's The Mass Psychology of Fascism in front of surveillance cameras (Albrechtslund and Dubbeld, 2002) .

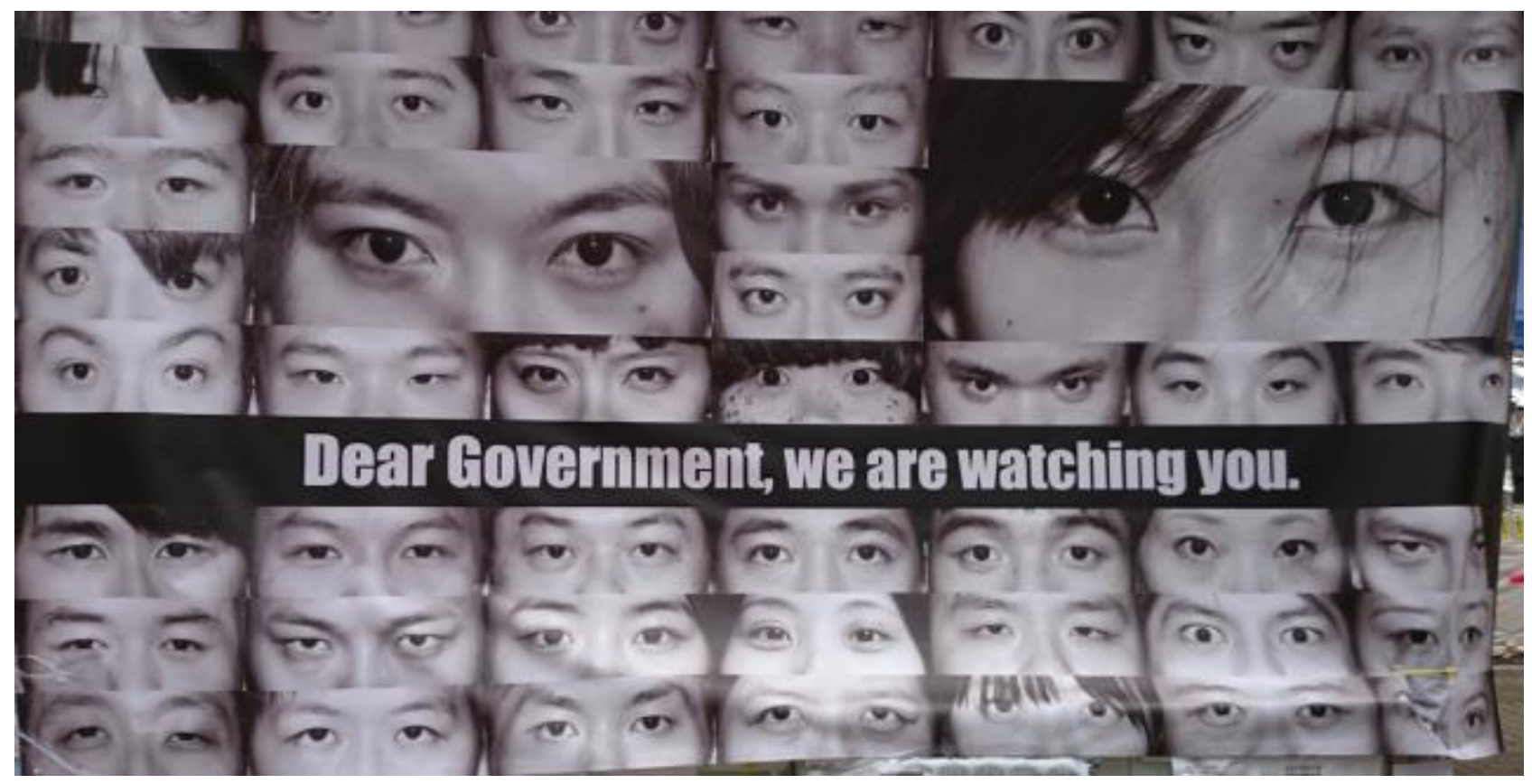

Figure 29, Hong Kong

Mobile phones and other digital technologies are changing the nature of surveillant landscapes and the kinds of interaction orders they make possible in other ways as well. Social media apps such as Facebook increasingly include functions that allow people to 'check-in' at particular locations and detect other users in those locations, and location-based dating apps such as Tindr and Grinder allow users to search for potential romantic partners within a certain geographical radius. The increasing 'layering' of space which digital technologies afford has made possible all sorts of new configurations for 'mutual monitoring' (Jones, 2005, 2009), as well as making 'lateral surveillance' (Andrejevic, 2005) not just a matter of keeping an eye out for potential threats, but also of keeping an eye out for potential friends. 


\section{Historical Bodies}

The last dimension of surveillant landscapes I will discuss is that of the 'historical body'. For the Scollons $(2003,2004)$, the idea of the historical body is used to talk about how tools, interactions and social practices in the external environment become internalized-sedimented into people in the form of habits, thoughts and bodily dispositions. This sense that surveillant architectures and the kinds of social relationships they encourage do not just exist externally, but end up getting 'into people's heads' and affecting the ways they inhabit their own bodies is, of course, central to Foucault's understanding of the panopticon. The key to the operation of the panopticon is not the fact that the prisoners are being watched, but the fact that the watcher is never visible to them, and so they are never sure whether they are being watched or not. As a result, they end up watching themselves. As Foucault (1995: 210) puts it, 'the major effect of the panopticon (is) to induce in the inmate a state of conscious and permanent visibility that assures the automatic functioning of power.' The same is true of the kinds of surveillant environments I discussed in the previous two sections: they operate not just through externally enforcing regimes of visibility, but also by causing citizens to internalize these routines of being watched and of watching others, of 'being on their best behavior', and of being alert to others who might not be.

When it comes to surveillant landscapes, however, there is another side to the 'historical body' as well, for just as an individual's 'history' of being watched over many moments and across many social situations gradually becomes sedimented into that individual's consciousness and bodily dispositions, the individual also creates an external historical body through all of the information that has been gathered about him or her over countless episodes of surveillance, information that sometimes comes to determine the kinds of surveillance practices he or she is subjected to in the future. Many surveillant landscapes, in fact, such as those making use of biometric information, depend for their operation on being able to recognize particular individuals and confirm their identities. 
These externalized 'historical bodies' take on many textual and material forms including stored CCTV footage, government records, and databases held by telecom companies of all of our phone calls and the physical locations that have been logged by our phones' GPS systems. They have been referred to by surveillance scholars in a variety of ways, as, for example 'second selves' (Andrejevic, 2003: 137), 'capta shadows' (Clarke, 2014) and, most famously, 'data doubles' (Haggerty and Ericson, 2000). The most important aspect of these 'data doubles' is the way they reveal how surveillant landscapes function to make their inhabitants 'legible', how they, for example, reduce individuals to particular characteristics or past actions and use those characteristics or actions to make judgments about identities or intentions. As Hagerty and Ericson (2006: 4) put it:

Surveillance technologies do not monitor people qua individuals, but instead operate through processes of disassembling and reassembling. People are broken down into a series of discrete informational flows which are stabilized and captured according to pre-established classificatory criteria. They are then transported to centralized locations to be reassembled and combined in ways that serve institutional agendas.

Another important aspect of data doubles highlighted in this quote is how they operate to collapse the space of surveillant landscapes, linking behaviors observed at one particular time and in one particular place to countless other times and places, so that it is not just a matter of us carrying around the habit of being watched within our consciousness and bodily hexis, but also of our history of being watched literally following us from place to place like a shadow. And so what we are confronted with in surveillant landscapes is not just the gaze of the watcher, but also an image of ourselves reflected back to us in the practices of surveillance to which we are subjected. 
Nowhere is this more evident than in airport security check points, where passengers develop practiced ways of complying with surveillance rituals, taking off their shoes, raising their arms when they are subjected to pat downs. But their ability to pass successfully through these rituals is also dependent upon information gathered about them in past encounters with authorities, inscribed in computer databases, on 'terrorist watch lists' or in the granting of 'priority status' which might entitle them to 'fast track' processing, and every time they participate in this ritual, answering questions in particular ways, either being searched or not, their actions generate even more information which will follow them into subsequent surveillance rituals. As we transverse surveillant landscapes we leave traces. Landscapes become the surfaces upon which we write our historical bodies. They remember us, record our activities, recognise us when we return to them, and feed our past actions back to us.

As surveillant landscapes are increasingly augmented with the ability to recognize and remember individuals and to alter their surveillance techniques based on what they 'know' about their inhabitants, they come to constitute feedback loops through which the internalized 'historical body' and the externalized 'historical body' develop in a kind of symbiotic relationship. Sometimes this occurs in 'real-time', as with speed limit signs such as that shown in Figure 30 which project the driver's speed back to him or her as they pass it, allowing them to compare how fast they are going with the permissible speed limit, an operation of surveillance which may result both in an immediate response by the driver as well as a more long-term alteration of their driving habits. And sometimes this occurs in more gradual ways, with the physical environment slowly altering based on the long term surveillance of behaviors and habits of its inhabitants; lights may appear on street corners or benches may be installed in railway stations based on information collected through sensors, CCTV cameras, or even human surveillance about how people use these spaces. 


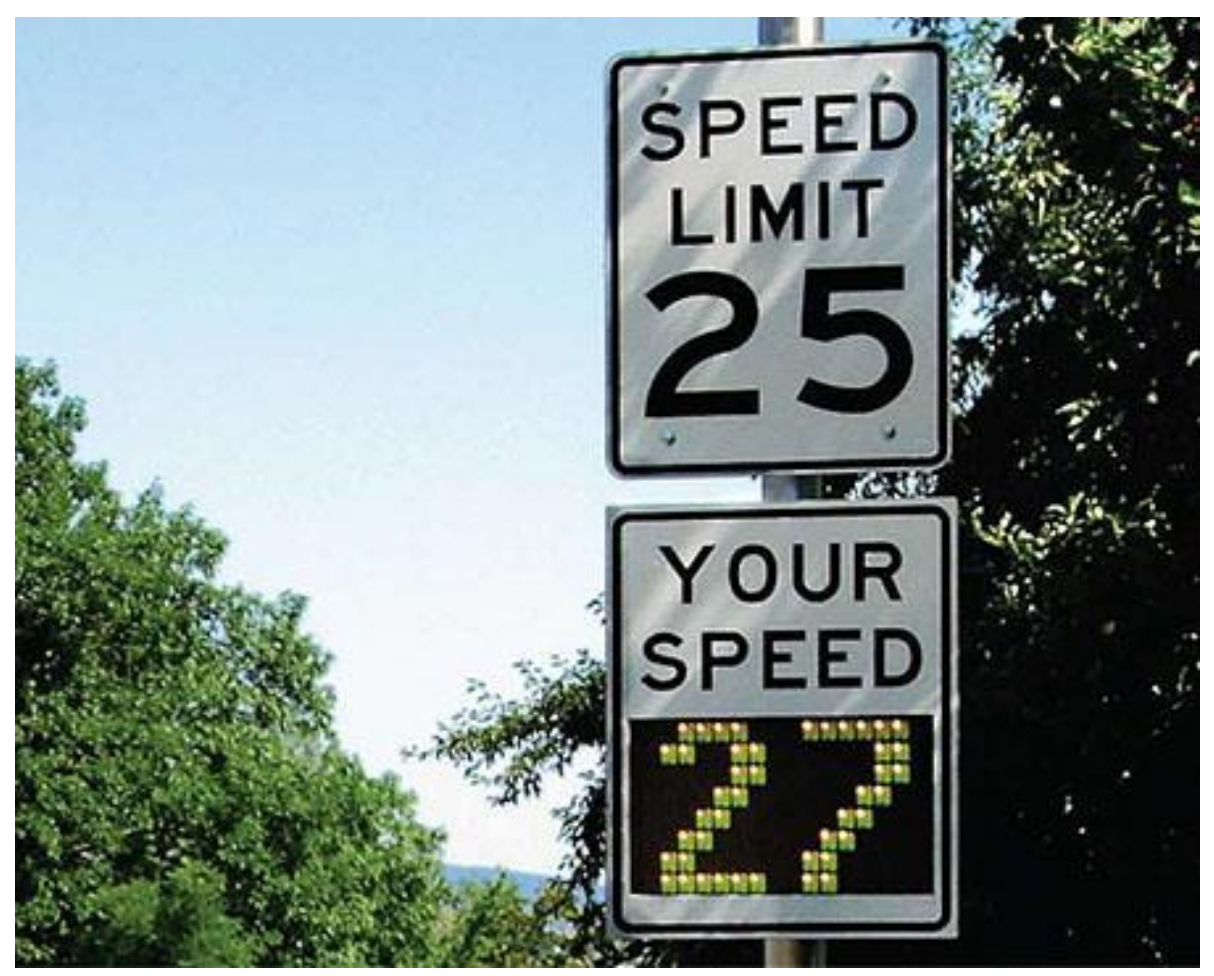

Figure 30, US Federal Highway Administration

(https://safety.fhwa.dot.gov/speedmgt/ref mats/fhwasa12004/)

Mobile digital technologies create even more ways for our internalized and externalized historical bodies to interact with whatever environment in which we find ourselves. Most obviously, they allow us to carry our past interactions with particular places with us into the future, so, for example, our Google maps app is able to recommend to us a certain route through a city based on routes that we have taken before. More importantly, however, these technologies make it easier for surveillant landscapes to detect our presence, to identify us, and to gather information about us that we may not be aware that we are making available. In the beginning of this article I already gave the example of the Wi-Fi spot on the bus, whose use requires customers to reveal personally identifiable information, and the mTicket app, which asks users to give it access to information stored on their phones such as their location. Such forms of mobile digital surveillance are increasingly common. Figure 31, for example, is a sign in the window of Philtz Coffee in San Francisco which informs customers that the establishment is using the Euclid system, an in-store customer identity and 
behavior system which allows them to identify customers that enter the store, review their past purchasing behavior, and recommend new purchases to them.

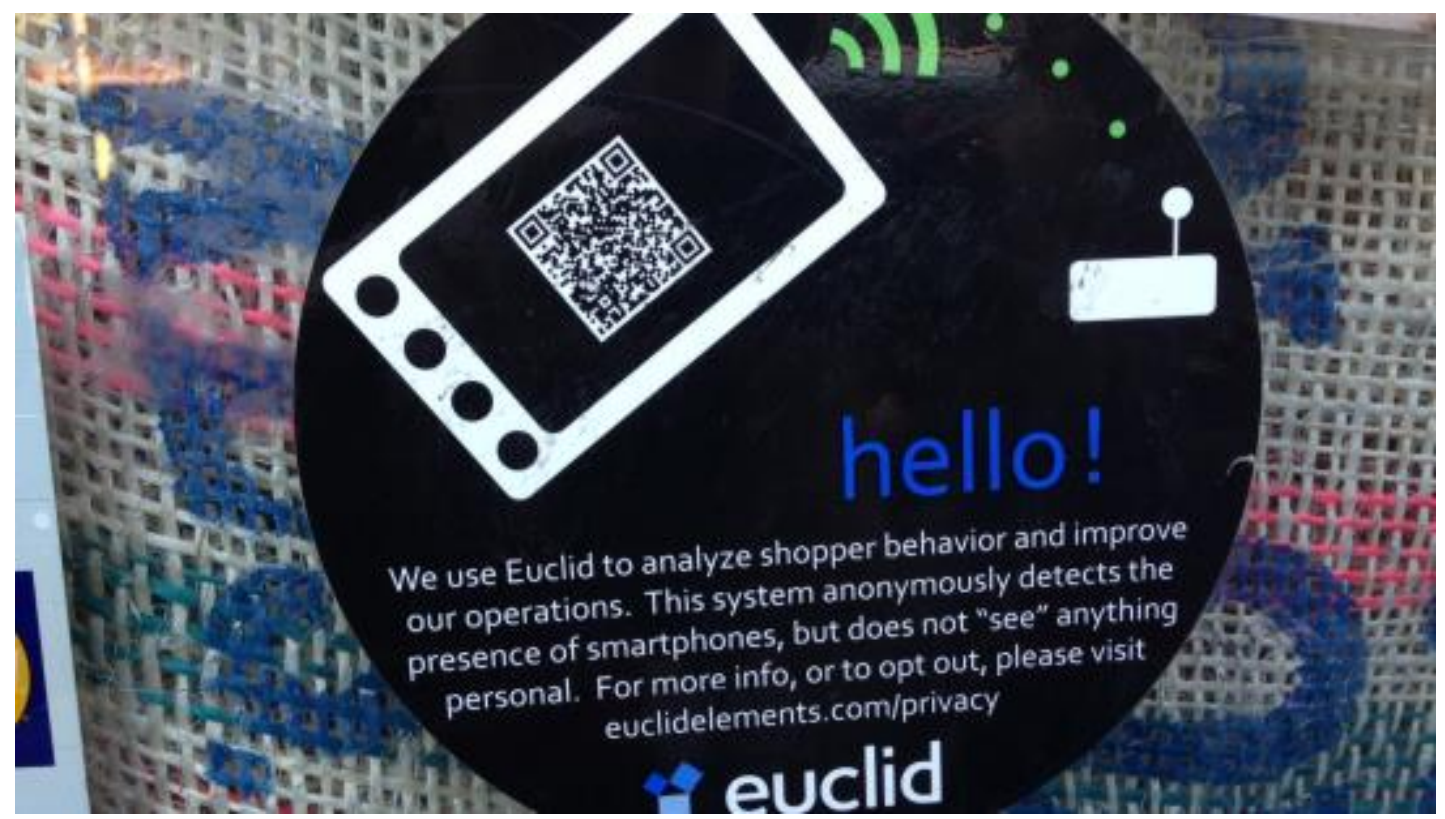

Figure 31, San Francisco, CA, USA

The ways in which our transactions in and interactions with physical environments are recorded and interpreted has consequences beyond the individual consumer/citizen, potentially altering broader political and economic realities. One example of this is the rise of 'geodemographics', the practice of publishing statistics of information gathered through surveys, sensors, or surveillance cameras about things like traffic, crime, and the socioeconomic status of people who live in particular areas. Such information inevitably has the effect of altering the way people interact with these spaces in the future so that, for example, businesses might avoid setting up shop in 'high crime areas', further diminishing employment opportunities in those areas and making it more likely that inhabitants will resort to criminal behavior (Dalton \& Thatcher, 2015; Phillips and Curry, 2003).

\section{Conclusion}

The main point I wish to make with the framework I laid out in this article is that surveillant landscapes are not just a matter of material and semiotic objects, that they are comprised not just of 
cameras and sensors and metal detectors and warning signs; they are complex assemblages of discourses, bodies, technologies, and social relationships which help to regulate the flows of people, goods, and information through our societies. This is particularly true in cities which, as Amin and Thrift $(2016: 36,39)$ describe it, are increasingly becoming complex adaptive systems 'awash with sensors and processors nested in street technologies, public infrastructures, buildings, homes and offices, and all kinds of mobile device' and 'governed by the balance of force between many authority structures - corporate and institutional, technical and infrastructural, computational and cartographic, social and symbolic, codified and informal' (see also Dovey, 2010). Cities are not just 'containers' for our interactions, they are networks of flows (Castells, 2000) in which material architectures serve to create and maintain the 'information architectures' which govern the way people and their interactions are distributed within and across physical spaces.

What this means for the study of linguistic landscapes is that the analysis of discrete discursive phenomena (such as shop signs) without reference to the ways they function within these complex systems is becoming increasingly untenable, as is the analysis of linguistic landscapes as 'read only' texts in ways that ignore their abilities to read their readers and to adapt to different circumstances. In a sense, nearly all aspects of the built environment are either directly or indirectly implicated in practices of surveillance and social control, contributing to both the organization of everyday encounters and to the the broader organization of social life. Related to this is the fact that even when we consider aspects of discourse and text in the built environment, we must remember that often the most important discourse is that which is hidden from us, operating beneath the surface of the linguistic landscape in the form of algorithms which sort and analyze and respond to the ways people interact with their environments and with one another. In other words, scholars of linguistic landscapes must eventually confront the fact that we cannot fully understand physical spaces without taking into account how they interact with what Kitchin and Dodge (2011) call code/space. 
At the same time, we must also remember that 'information architectures' are not just found in spaces that are 'augmented' (Manovich, 2006) by digital technologies. All spaces potentially constitute 'information architectures' insofar as they operate to regulate the 'mutual monitoring possibilities' (Goffman 1964:135) of the social actors who inhabit them and pass through them; this is as true for spaces fitted with 'old technologies' such as doors, windows, courtyards, guard towers and other features that allow people to be observed (Locke, 2010), as it is for those equipped with sophisticated 'covert devices and thermal imaging cameras'.

Finally, what this framework highlights is the degree to which surveillant landscapes function to help create certain social identities and social relationships, thereby operating in the service of particular ideologies and power structures. In most of the examples in this paper surveillant landscapes can be seen to be supporting the ideological agenda of neoliberalism, enforcing the increased privatization and commercialization of public space, segregating and excluding nonconsumers, and creating at least the illusion of what Bauman (1993) has referred to as 'pure space', in the same way the rituals of exclusion and forms of surveillance developed during times of the Plague, as Foucault (1995) points out, were designed to keep the medieval town 'clean'. Surveillant landscapes are part of what Epstein (1997:139) refers to as the 'architecture of fortification' of contemporary life in neoliberal nations, designed not just to protect citizens against 'dangerous others', but to create as 'dangerous' by excluding them or subjecting them to constant monitoring. From this perspective, attention to surveillant landscapes must be part of any approach in critical linguistics to understanding issues such as migration, the discursive construction of terrorism, the rise of new forms of nationalism, and the ongoing maintenance of social inequality. In the same way, as Coleman (2005:131) argues, the study of surveillance practices needs 'to be placed within wider debates about continuing urban inequality and the meaning of spatial justice.' 
At the same time, this framework also points to 'cracks' in surveillant landscapes and reveals tactics that citizens, consumers, and other victims of surveillance can use to re-signify discourses in place, reconfigure interaction orders, and re-inscribe new historical bodies onto surveillant landscapes. Some examples of this were mentioned above, such as the appropriation of of the genre of the surveillance sign in anti-government protests in Hong Kong, the use of mobile phones by citizens in encounters with police and at demonstrations, and playful bodily performances in front of surveillance cameras such as those engaged in by the Surveillance Camera Players. Other examples include the staged destruction of CCTV cameras by protesters in Greece described by Kitis and Milani (2015), and the use by citizens of special wallets or bags that prevent the detection of their mobile phones or the surreptitious reading of the RFID chips in their passports or ID cards (Yoshimi \& Hayles, 2009).

The fact is, it is the very the characteristics of surveillant landscapes highlighted by this model their indexical, interactive and corporal nature, the fact that they are dynamic and socially constructed as people move through them, interpreting them and negotiating different relationships with their authors and with other people in them — that make them vulnerable to subversion. For de Certeau (1984), writing long before the explosion of CCTV cameras, navigating through city streets is inherently an exercise in reading the relationships of power and surveillant possibilities imbedded in the urban architecture and searching for 'cracks', opportunities to negotiate different degrees of visibility and legibility through 'multiform, resistance, tricky and stubborn procedures that elude discipline without being out-side the field in which it is exercised' (p. 96). 'Walking' itself, he argued, is an exercise in resistance: 'since the crossing, drifting away, or improvisation of walking privilege, transform or abandon spatial elements' (p. 98). In this way, he writes, 'the city is left prey to contradictory movements that counter-balance and combine themselves outside the reach of panoptic power' (p. 95). 


\section{References}

Althusser, L. (2008). On ideology. London: Verso Books.

Albrechtslund, A., \& Dubbeld, L. (2002). The plays and arts of surveillance: Studying surveillance as entertainment. Surveillance \& Society, 3(2/3).

Amin, A., \& Thrift, N. (2002). Cities: Reimagining the urban. Oxford: Polity.

Amin, A., \& Thrift, N. (2016). Seeing like a city. Cambridge, UK ; Malden, MA: Polity Press.

Andrejevic, M. (2003). Monitored mobility in the era of mass customization. Space and Culture, $6(2), 132-150$.

Andrejevic, M. (2005). The work of watching one another: Lateral surveillance, risk, and governance. Surveillance \& Society, 2(4), 479-497.

Baumann, Z. (1993). Postmodern ethics. Oxford: Oxford University Press.

Ben-Rafael, E., Shohamy, E., Amara, M. H., \& Trumper-Hecht, N. (2006). Linguistic landscape as symbolic construction of the public space: The case of Israel. International Journal of Multilingualism, 3(1), 7-30.

Blommaert, J. (2013). Ethnography, superdiversity and linguistic landscapes: Chronicles of complexity. Bristol : Multilingual Matters. 
Castells, M. (2000). The rise of the network society. Oxford; Malden, Mass: Wiley-Blackwell.

Clarke, R. (2014). Persona missing, feared drowned: the digital persona concept, two decades later, Information Technology \& People, 27 (2), 182 - 207.

Cole, M. (2002). Signage and surveillance: Interrogating the textual context of CCTV in the UK. Surveillance \& Society, 2(2/3). Retrieved from http://ojs.library.queensu.ca/index.php/surveillanceand-society/article/view/3387

Coleman, R. (2005). Surveillance in the city: Primary definition and urban spatial order. Crime, Media, Culture, 1(2), 131-148.

Coleman, R. \& Sim, J. (2000). "You'll never walk alone”: CCTV surveillance, order and neoliberal rule in Liverpool city centre, British Journal of Sociology, 51(4): 623-639.

de Certeau, M. (1984). The practice of everyday life. Berkeley, CA: University of California Press.

Dalton, C. M., \& Thatcher, J. (2015). Inflated granularity: Spatial 'Big Data' and geodemographics. Big Data \& Society, 2(2), 1-15.

Dovey, K. (2010). Becoming places. London: Routledge.

Epstein, D. (1997) Abject terror: a story of fear, sex and architecture. In N. Ellin (ed.) The architecture of fear (pp. 133-142). New York: Princeton Architectural Press.

Foucault, M. (1970) The order of things: An archaeology of the human sciences. London: Tavistock. 
Foucault, M. (1995). Discipline and punish: The birth of the prison. New York: Vintage.

Goffman, E. (1959). The presentation of self in everyday life. New York: Doubleday.

Goffman, E. (1963). Behavior in public places: Notes on the social organization of gatherings. New York: The Free Press.

Goffman, E. (1964), 'The neglected situation', American Anthropologist, 66: 133-6.

Goffman, E. (1983). The interaction order: American Sociological Association, 1982 presidential address. American Sociological Review, 48(1), 1-17.

Graham, S. D. N. (2005). Software-sorted geographies. Progress in Human Geography, 29 (5), $562-580$

Haggerty, K. D., \& Ericson, R. V. (2000). The surveillant assemblage. British Journal of Sociology, $51(4), 605-622$.

Haggerty, K. D., \& Ericson, R. V. (2006). The new politics of surveillance and visibility. Toronto: University of Toronto Press.

Halliday, M.A.K \& Mattheison, C. (2014). An Introduction to functional grammar. London: Routledge. 
Jones, R. H. (2005). Sites of engagement as sites of attention: Time, space and culture in electronic discourse. In S. Norris \& R. H. Jones (eds.) Discourse in action: Introducing mediated discourse analysis (pp. 144-154). Abingdon: Routledge.

Jones, R. (2009) Inter-activity: How new media can help us understand old media. In C. Rowe and E. Wyss (eds.) New media and linguistic change (pp. 11-29). Cresskill, NJ: Hampton Press.

Jones, R.H. \& Li, N. C. H. (2016) Evidentiary video and "professional vision" in the Hong Kong umbrella movement. Journal of Language and Politics, 15 (5). pp. 569-591.

Katz, J. E. (2006). Magic in the air: Mobile communication and the transformation of social life. New Brunswick, NJ: Transaction Publishers.

Kerfoot, C., \& Hyltenstam, K. (2017). Entangled discourses: South-North orders of visibility. London: Routledge.

Kitchin, R., \& Dodge, M. (2014). Code/Space: Software and everyday life. Cambridge, Mass.: The MIT Press.

Kitis, D. E., \& Milani, T. M. (2015). The performativity of the body: Turbulent spaces in Greece. Linguistic Landscape, 1(3), 268-290.

Lefebvre, H. (1991). The production of space. Oxford: Basil Blackwell.

Locke, J. L. (2010). Eavesdropping: An intimate history. Oxford: Oxford University Press.

Manovich, L. (2006). The poetics of augmented space. Visual Communication, 5(2), 219-240. 
Markus, T. A. (1994). Buildings and power: Freedom and control in the origin of modern building Types, London: Routledge.

Markus, T. A., \& Cameron, D. (2002). The words between the spaces: Buildings and language. London: Routledge.

Mirzoeff, N. (2011). The right to look. Critical Inquiry, 37 (3): 473-496.

Monahan, T. (2006). Preface. In T. Monahan (ed.) Surveillance and security: Technological politics and power in everyday life (pp. ix-xi). New York: Routledge.

Newman, O. (1972). Defensible space:. New York: Macmillan.

Norris, S. (2004). Analyzing multimodal interaction: A methodological framework. London: Routledge.

Otter, C. (2008). The Victorian eye: A political history of light and vision in Britain, 1800-1910. Chicago: University of Chicago Press.

Phillips D. \& Curry M. (2003). Privacy and the phenetic urge: Geodemographics and the changing spatiality of local practice. In: Lyon D (ed.) Surveillance as social sorting: Privacy, risk, and digital discrimination (pp. 137-152). New York, NY: Routledge.

Scollon, R. (2001). Mediated discourse: The nexus of practice. London: Routledge. 
Scollon, R., \& Scollon, S. W. (2003). Discourses in place: Language in the material world.

London: Routledge.

Scollon, R., \& Scollon, S. W. (2004). Nexus analysis: Discourse and the emerging internet.

London: Routledge.

Scott, J. (1999). Seeing like a state: How certain schemes to improve the human condition have failed. New Haven: Yale University Press.

Shohamy, E., \& Gorter, D. (eds.) (2008). Linguistic landscape: Expanding the scenery. New York: Routledge.

Wall, T., \& Linnemann, T. (2014). Staring down the state: Police power, visual economies, and the 'war on cameras'. Crime, Media, Culture, 10 (2): 133-149.

Yoshimi, S., \& Hayles, N. K. (2009). RFID: Human agency and meaning in information-intensive environments. Theory, Culture \& Society, 26(2-3), 47-72. 